\title{
EFFECTS OF EDUCATIONAL AND METROPOLITAN CONTEXT ON U.S. \\ BLACK INTERMARRIAGE
}

\author{
A Dissertation \\ by \\ DANNY ELWORTH MALONE JR
}

\begin{abstract}
Submitted to the Office of Graduate and Professional Studies of Texas A\&M University in partial fulfillment of the requirements for the degree of

DOCTOR OF PHILOSOPHY
\end{abstract}

\begin{abstract}
Chair of Committee, Dudley L. Poston, Jr. Committee Members, Mary E. Campbell Mark Fossett Tommy J. Curry

Head of Department, Dennis O'Heran
\end{abstract}

May 2017

Major Subject: Sociology

Copyright 2017 Danny Elworth Malone Jr. 


\begin{abstract}
Both individual and structural level analyses have been conducted on black intermarriage extensively, but how well have they been measured? This dissertation examines the effects of education and metropolitan contexts of black intermarriage in the United States. Evidence from 2008-2014 IPUMS-ACS data suggest that education and the distance in education level between spouses predict greater odds of intermarriage for both black men and women. Logistic regression and HLM modeling were used to analyze the relationship between education, metropolitan context and predating the odds of intermarriage for both black men and women. When context is considered, there is a stark contrast among gender lines in the prediction of intermarriage. Findings indicate that both education and context are important for predicting the likelihood of intermarriage for black men. The picture is not so clear for black wives.
\end{abstract}




\section{DEDICATION}

This dissertation is dedicated to my angel in heaven, my daughter, Grace. While your presence was not long, you brought a LIGHT into my life. My heart dropped when God called you home. Mom and Dad will always love you, and I know you are watching us from above. 


\section{ACKNOWLEDGEMENTS}

I would like to thank my committee chair, Dr. Dudley L Poston, Jr, and my committee members, Dr. Mary Campbell, Dr. Mark Fossett, and Dr. Tommy J Curry, for their guidance and support throughout the course of this research. More importantly, each of these wonderful scholars and individuals has pushed me to challenge my own limitations and for that, I am forever grateful.

Thanks to my friends, colleagues, and the TAMU sociology department faculty and staff for making my time at Texas A\&M University full of life experiences.

Finally, thanks to my wife, Stephanie for loving me even when I am tough to love. I also want to thank my parents for showing me that it is about "showing up and showing out" in life. Thanks to my younger brothers for being the reason I push myself to the limit. I would like to say thank you to my Lord and Savior Jesus Christ. Without HIM, I am NOTHING. 


\section{CONTRIBUTORS AND FUNDING SOURCES}

Part 1, faculty committee recognition

This work was supervised by a thesis (or) dissertation committee consisting of Professor Dudley L Poston Jr -Chair and Professor(s) Mary E. Campbell and Mark Fossett of the Department of Sociology and Professor(s) Tommy J Curry of Department of Philosophy.

Part 2, student/collaborator contributions

All work for the thesis (or) dissertation was completed independently by the student.

Funding Sources

No funds were needed to conduct this project. 


\section{TABLE OF CONTENTS}

\section{Page}

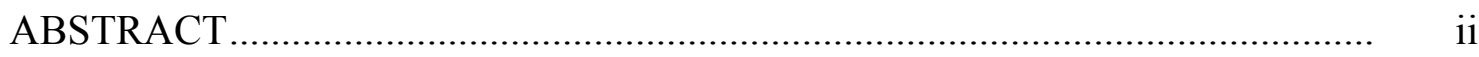

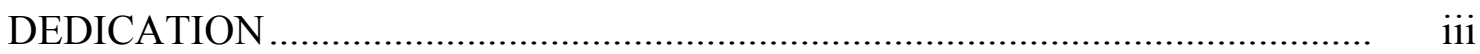

ACKNOWLEDGEMENTS ....................................................................... iv

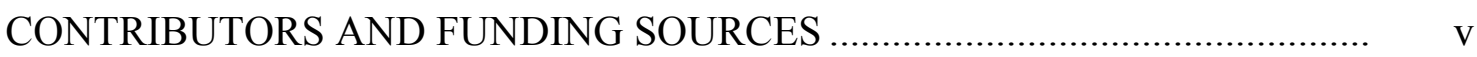

TABLE OF CONTENTS .......................................................................... vi

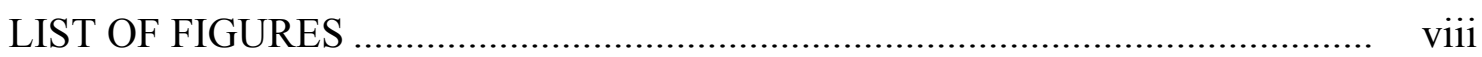

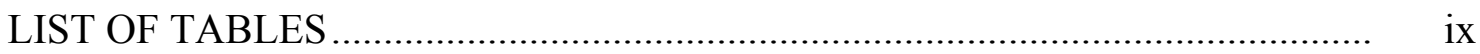

CHAPTER I INTRODUCTION ……………........................................... 1

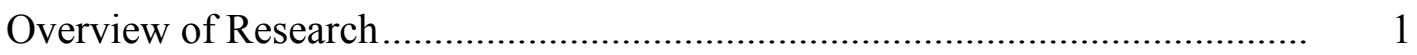

CHAPTER II LITERATURE REVIEW …………......................................... 12

General Overview of Intermarriage in the U.S............................................. 12

Determinants of Intermarriage ................................................................... 14

Structural Assimilation Theory: Educational Mobility...................................... 18

Merton's Status Exchange Theory .................................................................... 19

Setting the Context: Status Exchange is Beyond Individual Wants ................... 23

Issues Concerning Modeling Context................................................................. 25

CHAPTER III DATA AND METHODS ………............................................... 29

Data, Sample, and Sample Restrictions …………………........................... 29

Individual Level Data ................................................................................ $\quad 30$

Issues with Data .................................................................................... 35

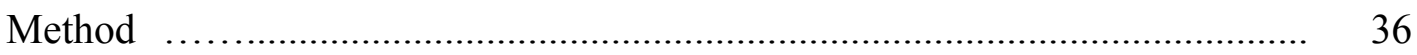

Logistic Regression............................................................................... 36

Introduction to Multilevel Modeling ................................................................ 38

Issues Concerning Modeling Context .............................................................. 41

Summary ................................................................................... 44 
CHAPTER IV LEVEL ONE ANALYSES ....................................................... 45

Hypotheses and Operationalization ........................................................ 45

Descriptive Statistics....................................................................... 47

Logistics Regression Diagnostics ........................................................... 49

Logistics Regression Results ................................................................... 51

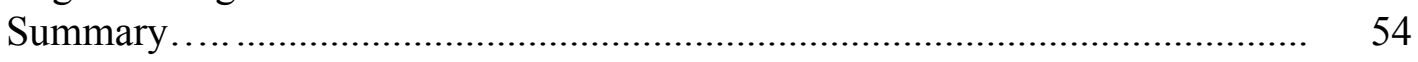

CHAPTER V MULTILEVEL ANALYSES OF INTERRACIAL

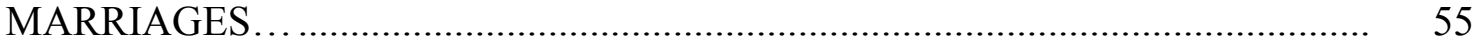

Hypotheses and Operationalization ......................................................... 56

Descriptive Statistics of Contextual Variables .......................................... 58

Multilevel Results ................................................................................... 59

Multilevel Models ...................................................................................... 61

Cross-level Interactions .................................................................... 64

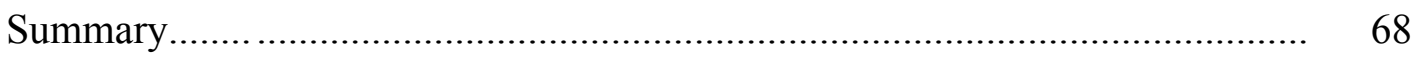

CHAPTER VI CONCLUSIONS AND FUTURE RESEARCH ....................... 70

Level One Analyses ........................................................................ $\quad 72$

Multilevel Analyses ............................................................................... 76

Discussion and Future Research ....................................................... 82

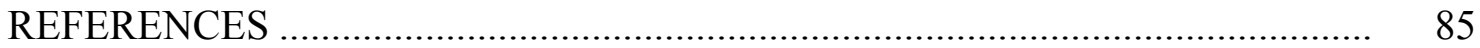




\section{LIST OF FIGURES}

Page

Figure 1. Contextual-Effects Model.................................................40 


\section{LIST OF TABLES}

Page

Table 3-1. Married Black Men in Metropolitan Statistical Areas, 2008-2014.

Table 3-2. Married Black Women in Metropolitan Statistical Areas, 2008-2014

Table 4-1. Descriptive Statistics, 1,675 Black Men Residing in Metropolitan Statistical Areas, 2008-2014

Table 4-2. Descriptive Statistics, 1,544 Black Women Residing in Metropolitan Statistical Areas, 2008-2014

Table 4-3. Logistic Regression Results: Educational Mobility for Black Husbands in Metropolitan Statistical Areas.

Table 4-4. Logistic Regression Results: Educational Mobility for Black Wives in Metropolitan Statistical Areas.

Table 4-5. Logistic Regression Results: Status Exchange Theory for Black Husbands in Metropolitan Statistical Areas.

Table 4-6. Logistic Regression Results: Status Exchange Theory for Black Wives in Metropolitan Statistical Areas..........................................54

Table 5-1. Descriptive Statistics of Level-2 Variables: Black Husbands Models, Metropolitan Statistical Areas, 2013

Table 5-2. One-way ANOVA Model, Black Husbands

Table 5-3. One-way ANOVA Model, Black Wives.

Table 5-4. Odds Ratios and Coefficients for Individual and Group Size

Characteristics on the Likelihood of Being Intermarried for Black Men

Table 5-5. Odds Ratios and Coefficients for Individual and Racial Heterogeneity Characteristics on the Likelihood of Being Intermarried for Black Men... 
Table 5-6. Odds Ratios and Coefficients for Individual and Black Sex Ratio Characteristics on the Likelihood of Being Intermarried for Black Men.......64

Table 5-7. Odds Ratios and Coefficients for Cross-Level Interactions of Individual and Group Size Characteristics on the Likelihood of Being Intermarried for Black Men...................................................66

Table 5-8. Odds Ratios and Coefficients for Cross-Level Interactions of Individual and Racial Heterogeneity Characteristics on the Likelihood of Being Intermarried for Black Men.

Table 5-9. Odds Ratios and Coefficients for Cross-Level Interactions of Individual and Black Sex Ratio Characteristics on the Likelihood of Being Intermarried for Black Men. .68 


\section{CHAPTER I}

\section{INTRODUCTION}

\section{Overview of Research}

Black interracial marriage in the United States is known to have gender differentials in respect to black men marrying out at a much higher rate than black women (Crowder and Tolnay 2000; Jacobs and Labov 2002). The intention of this dissertation is to add to this literature by specifically investigating the degree to which education and spatial context influence the odds of intermarriage for both black men and black women.

I accomplished this goal by analyzing how both individual level and structural level determinants impact the interracial marriage decisions of black men and black women. I estimated multilevel logistic regression equations where intermarriage is the dependent variable. The analysis included structural level variables because marriages are not solely the products of individual decisions. Thus, intermarriage was predicted not only at the individual level using the educational attainment of the black spouse but also with contextual variables based on the characteristics of the metropolitan statistical areas (MSAs) where each couple lived. At the individual level, I specifically examined how educational attainment of the black spouse predicted the odds of intermarriage. Also, I investigated whether the educational gap between spouses influenced the odds of intermarrying interracially, enabled me to test Merton's status exchange theory (discussed below). The contextual variables to be included as independent variables 
were group size, sex ratio, and racial heterogeneity (to be described in detail in Chapter III).

Education has been the primary characteristic of interest as a predictor of interracial marriages (Tucker and Mitchell-Kernan 1990; Qian 1997; Fu 2001; Rosenfeld 2005; Gullickson 2006). Education creates and maintains an economic and a social status for the couple. One of the primary questions of this dissertation not only concerned the effect of education per se on the odds of intermarriage for blacks but whether the gap between the education level of the spouses affected the odds of intermarriage. Two different theories have been set forth to address the issue of intermarriage, namely, educational mobility and status exchange. Educational mobility stresses that as blacks increase their level of education so do their odds of interracial marriage (Merton (1941) asserted that there was an "exchange" of social status and education status between blacks and whites for a marriage to materialize. I will now provide an overview of each theory.

Educational mobility is borne out of structural assimilation theory that argued interracial marriages increase with educational mobility. Specifically, proponents of educational mobility assert that since the education system of the U.S. emphasis democratic and universalistic norms, group barriers can be broken down allowing for increased likelihood of interracial unions (Gullickson 2006; Lieberson and Waters 1988).

Merton's Status Exchange theory has been one of the longest standing theories in sociology concerning how intermarriages among whites and blacks occur in a developed 
and modernized country such as the United States. In 1941, Robert Merton hypothesized that for intermarriage between a black male and a white female to materialize, there would have to be an "exchange" to legitimate the union. Specifically, this exchange was a "race for social prestige" scenario where a high status African American male could "trade" this socioeconomic status for the racial status of his white wife. Furthermore, important studies in the field of intermarriage using status exchange theory (Kalmijn 1993; Qian 1997; Rosenfeld 2005; Gullickson 2006) all demonstrated how individual level factors such as race, gender and education influence the likelihood of intermarriage.

Along with individual-level determinants, contextual variables such as sex ratio, group size, and racial heterogeneity should also be relevant in predicting intermarriage among blacks (Cready and Saenz 1997; Crowder and Tolnay 2000; Hou and Myles 2013). The upcoming pages briefly introduce how Merton's status exchange theory empirically plays out. Next, I then cover some issues with current studies using multilevel models, and I provide some insights on the importance of a proper statistical approach using structural level variables.

Merton's status exchange theory presumes that a racial hierarchy exists in the U.S. society in its conception of highly educated black males marrying white females with less education than their black spouses. Some studies confirm and deny the central thesis of Merton's status exchange theory based on how their models are set up. Rosenfeld (2005) argued that status exchange exists while Gullickson Fu and Kalmijn (2010) refuted that claim by arguing for model misspecification by Rosenfeld. These 
studies only dealt with the education difference between husband and wife as the primary determination of whether or not status exchange theory was the dominant trend in black intermarriage. Also, I add that whenever there is support for status exchange theory, it is generally when black men marry white women and not the converse. My dissertation directly tests status exchange theory by examining education disparity between both black men and black women married to white spouses.

While context per se has not been considered in this particular debate about status exchange theory, several studies did take context into consideration in respect to predicting intermarriage.

Considering the effect of context is critical for not only status exchange theory but also for mate selection overall. Cready and Saenz (1997) and Crowder and Tolnay (2000) both use contextual-level variables to understand black intermarriage further. Each study finds that contextual variables are important in understanding black intermarriage patterns. Studies assessing status exchange outside of the U.S. also conclude that context, the country under study, has an impact on the prevalence of status exchange (Hou and Miles 2013; Gullickson and Torche 2014). Most find minimal support for status exchange in respect to black men but not for black women. While these studies offer a multilevel analysis that includes individual and contextual level variables, their contextual variables are disaggregated to the level of the individual which is a problematic statistical technique to draw conclusions. This dissertation uses currently developed statistical methods to estimate multilevel models in a more statistically appropriate manner. 
This dissertation analyzed the effects of education and metropolitan context on intermarriages involving U.S. black men and involving U.S. black women. Beyond examining the gender differences in intermarriage, my dissertation also addressed Merton's status exchange theory using education disparity among spouses. I engaged in multilevel modeling. While many studies include both individual and contextual level variables in their assessment of status exchange theory, many do not use the more statistically approach. Specifically, when utilizing a multilevel approach, some of the research has disaggregated the contextual-level variables down to the individual level for analysis. Essentially, all persons in the same context would have the same values hence violating the assumption of independence that is basic for the use of classical statistical techniques (de Leeuw, 1992: xiv). A multilevel analysis requires an adjustment to the standard errors in respect to individual level characteristics and the dependent variable. This dissertation will address this matter and offer the use of a hierarchical modeling approach as the statistically preferred method for multilevel modeling.

\section{General Overview of Black Intermarriage}

Black intermarriages are defined as marriages that consist of one partner who racially identifies as a non-Hispanic $(\mathrm{NH})$ black and a spouse who identifies as other than NH black. Intermarriage has been on the rise in the United States since the 1960s (Lee and Edmonston 2005). While fewer than 2 percent of marriages in the United States were interracial marriages in 1960 , as of 2010 , these unions now constitute just about 10 percent of all marriages (U.S Census Bureau 2010). Increases in the number of 
interracial marriages between different racial groups are viewed as an indirect indicator of declining social distance among racial groups (Qian and Lichter 2004; Gordon 1964). But the increases are not even along gender lines. Black men are at least twice as likely to marry someone outside of their racial group than are black women (Qian 1997; Fu 2001; Jacob and Labov 2002; Qian and Lichter 2011). One of the main theories used to explain black intermarriage and one that could be used to understand the gender differential in black intermarriage is Merton's status exchange theory.

\section{Explanations for Black Intermarriage}

When analyzing interracial marriage trends for different racial groups, most of the research tends to focus on micro-level independent variables that are demographic and social. Which demographic factors are most prevalent in interracial marriages and how do they vary by particular racial combinations? Can we only rely on individuallevel characteristics to explain the formation of interracial marriages? What about sex differences within a racial group concerning interracial marriage?

The interracial marriage literature stresses educational attainment plays a significant role in the likelihood of interracial marriage (Kalmijn 1993). Education, especially attendance to college, facilitates increased contact with the majority group in a setting that is supposed to promote tolerance along with the racial assimilation of minority groups to the majority group (Lee and Edmonston 2005). One can assume, using educational attainment as a proxy for minority group-majority group contact that interracially married couples come into contact with one another either on college 
campuses or in the workplace.

Within this increased contact of different racial groups comes the idea of preference and opportunity. The study of marriage patterns only tells us which groups interact with each other; while important, this does not explain why people intermarry. It is the interplay of social forces that need our attention. We need to consider individual preferences for particular characteristics, the influence of the social group members, and the marriage market constraints. To this point, studies of online dating preferences for whites show racialized images of masculinity and femininity play a role in the dating and marriage outcomes (Feliciano, Robnett, Komaie 2009). Within this web of factors, the marriage patterns arise (Kalmijn 1998). Using these social forces to predict the likelihood of intermarriage, one might state that intermarried couples were likely paired together when their individual preferences were accounted for, the obligation to marry within their racial group was small, and the marriage market constraint was in their favor.

Another area of interracial marriage that tends not to get much attention beyond the descriptive statistics is the sex differentials that exist within racial groups. The sex differentials in intermarriage among African Americans note African American men tend to interracially marry two to three times more frequently than African American women (Tucker and Mitchell-Kernan 1990; Jacob and Labov 2002). If we focus on the factors most associated with the sex differentials in the marriage patterns, we can better predict the likelihood of intermarriage.

In short, the sociological relevance of interracial marriage lies in its internal 
racial, socioeconomic, and gender dynamics; it is not just a reflection of the boundaries that currently separate groups in society; it also represents the levels of cultural and socioeconomic change and dynamics in the society (Kalmijn 1998). Education, preferences, opportunities and the sex differentials are all essential for better understanding the likelihood of people intermarrying. My dissertation research seeks to flesh out these dynamics in detail by not only looking at the individual-level characteristics that are related to intermarriage, but also such contextual-level characteristics as sex ratios, racial heterogeneity, and group size.

\section{Problems with Studying Black Intermarriage}

While black interracial marriage is a fascinating topic, its demographic and statistical analysis is not without problems. The first issue deals with the prevalence versus the incidence of marriage when using data from the American Community Survey (ACS) and the fact that education can change during a marriage. This issue can mislead researchers interested in the relationship between the odds of intermarriage and the level of education. In this section, I will discuss these problems and suggest one way to possibly overcome them to create a sound methodological foundation for my conducting my dissertation research.

One problem with the study of marriage is whether or not the research can identify if the marriage has been recently contracted (Qian and Lichter 2011). The main drawback of dealing with intact marriages is that some were contracted long before the Census interview and may not have been subjected to current market marriage 
opportunities and constraints (Qian and Lichter 2011). In other words, one or more of the independent variables may have occurred after the occurrence of the dependent variable of marriage; this problem is known in the demographic literature as simultaneity bias (Greenwood 1975). After the 1980 Census had been conducted, the questions about the number of times married and age at first marriage was dropped from the long form questionnaire. Selection biases exhibited by prevalence data can be overcome by using incidence data on recent marriages. The ACS replaced the long form census and in 2008, reintroduced the marriage order question and whether or not the marriage had been contracted within the past 12 months (Qian and Lichter 2011). In this research, I restricted my sample only to include couples currently in first marriages that were contracted within the recent twelve months of the interview.

I will discuss in more detail the issue of simultaneity bias. Simultaneity bias refers to a statistical issue wherein the characteristics to be employed as independent variables were measured after the occurrence of the dependent variable. Thus if we hypothesized that high education would be related to a higher likelihood of interracial marriage, we need to be sure the educational variable occurs before the marriage. Education, like age, can change over time, so we cannot assume that the education level people list on the ACS is the same one they had when they married. If the argument here is that higher educated black males are more likely to out-marry, then we need to know that the education of the black husband was completed before the marriage. None of the studies I have encountered in my review of the literature address this particular matter. One way to deal with the issue is to restrict the analysis to couples that have married 
within the twelve months of the interview. I employed this strategy in my dissertation.

In this introduction chapter, I have presented a project that investigates how black intermarriage patterns vary by sex of the black spouse at both the individual and contextual level. There is much research that has shown that while there is a positive relationship between the level of education of blacks and intermarriage, the same study points out that black men out marry quite more frequently than black women (Qian 1997; Jacobs and Labov 2002). Explanations for the outmarriage differential that will be tested here are educational mobility of blacks will lead to increased odds of intermarriage, while status exchange argues that most black-white intermarriages involve a high SES black spouse and a low SES white spouse. While education has been used as a primary predictor of intermarriage, the context has also been important in understanding intermarriage patterns (Hwang, Saenz, and Aguirre 1994; Hwang, Saenz, and Aguirre 1997). Contextual variables that have been known to influence intermarriage patterns are group size, group-specific sex ratio, and racial heterogeneity of the context (Blau 1982; Blau and Schwartz 1984; Anderson and Saenz 1994; Hou and Myles 2013). This project puts forth a multilevel logistic regression predicting the odds of intermarriage for both black men and women based on the education of the spouse and the context of the metropolitan statistical area (MSA). What makes my project distinct is that I will conduct a hierarchical linear model to allow variation at the contextual level to predict intermarriage which has not been done much at all in intermarriage research. In the next chapter, I detail the literature that guided my research: examining U.S. intermarriage in the U.S., individual and structural determinants of 
intermarriage, how educational mobility and status exchange inform us about black intermarriage, how understanding context and issues modeling context to understand further how context impact intermarriage patterns for black men and women. 


\section{CHAPTER II}

\section{LITERATURE REVIEW}

This literature review will provide an overview of previous research on intermarriage, and specifically on prevalence status exchange and black intermarriage in America. The chapter has six sub-sections: 1) a general summary of intermarriage trends in the U.S., 2) a review of the standard individual and contextual determinants of intermarriage, 3) a general overview of educational mobility and intermarriage, 4) a general overview of status exchange theory and how it has been modeled in analyses of intermarriage, 5) Merton's actual model of status exchange theory 6) issues with current multilevel modeling of status exchange theory. This chapter will conclude with my attempt to set forth a comprehensive and statistically appropriate multilevel model of status exchange theory so to better understand black intermarriage patterns.

\section{General Overview of Intermarriage in the US}

Until relatively recently, intermarriage in the U.S. was illegal in many states. It was deemed unconstitutional until the U.S. Supreme Court case of Loving vs. Virginia was brought about by Richard Loving, a white male, and his black and American Indian wife, Mildred Jeter. Lee and Edmonston (2005:5) wrote that anti-miscegenation laws prevented marriage between non-whites and whites from maintaining privilege and power that would support the beliefs of racial separation, difference, and purity among the racial groups. 
Interracial marriage in the United States has been on the rise since the Loving $v$. Virginia U.S. Supreme Court case in 1967. Most interracial marriages have a white spouse and spouse of color (Lee and Edmonston 2005). The Pew Research Center for Social and Demographic Trends found that interracial marriages have been on the rise since 1980, where 3.2 percent of all couples intermarried. Their data showed the level to be 6.8 percent in 2000, and 8.4 percent in 2010 (Pew Research Center 2012). When we delve deeper into the trends, there are noticeable differences among the racial/ethnic groups that interracially marry. While blacks, Asians, whites, and Latinos have all seen increases in interracial rates since the 1970s, blacks lag behind Latinos and Asians. More than a quarter of newlywed Hispanics (25.7\%) and Asians (27.7\%) in 2010 married a person of a different race while only 17.7 percent of blacks and 9.7 percent of white newlyweds married a person of a different race (Pew Research Center 2012). We can see that Hispanics and Asians were more likely to intermarry compared to blacks and whites. Changing patterns of interracial marriage are often used as an indicator of changing group boundaries and social distance (Qian and Lichter 2007).

Specifically looking at black intermarriage, we note there is a noticeable difference in outmarriage prevalence among black men and black women. Black men interracially married to white women constitute up to three-fourths of all black-white couples (Lichter and Qian 2004; Rosenfeld 2008; Qian and Lichter 2011). In the U.S., Qian and Lichter (2011) found that black-white marriages for black men increased from $4.7 \%$ in 1980 to $14.4 \%$ in 2008 , while black-white marriages for black women rose from $1.3 \%$ to $6.5 \%$. This means that black men marry white women at least twice as often as 
black women marry white men (Qian and Lichter 2011). According to the 2010 U.S. Census, $10.8 \%$ of married black husbands and $4.6 \%$ of married black wives had nonBlack spouses (U.S. Census 2010). As it pertains to black intermarriage, $8.5 \%$ of black husbands $(390,000)$ have white wives compared to only $3.9 \%$ of black wives $(168,000)$ having white husbands (U.S. Census 2010). This difference of out-marriage of black men compared to black women speaks to racial and gender aspects of intermarriage as a social phenomenon.

The focus of this dissertation on black-white marriage will be similar to earlier analyses of sociologist Robert K. Merton in his attempts to explain and better understand intermarriage differences between two racial groups in the United States (Rosenfeld 2005). I will cover Merton's research in a later section of this chapter.

\section{Determinants of Intermarriage}

In my second section, I cover the common determinants of intermarriage. The factors leading to intermarriage among various racial groups vary at the individual level and the structural or contextual level. The individual level determinants primarily focus on attributes of the individual that influence the rate of intermarriage, while "the structural theoretical perspective is concerned with the impact of a population's social characteristics and structure on its collective rate of intermarriage" (Anderson and Saenz 1994: 415). Characteristics at both levels have been found to impact the odds of intermarriage among Asians (Hwang, Saenz Aguirre 1994; Hwang, Saenz, Aguirre 1997), Blacks (Tucker and Mitchell-Kernan 1990; Cready and Saenz 1997; Crowder and 
Tolnay 2000; Hou and Myles 2013), and Hispanics (Anderson and Saenz 1994). Individual-Level Factors of Intermarriage

Among the individual level determinants of intermarriage, education (Tucker and Mitchell-Kernan 1990; Kalmijn 1993; Qian 1997; Fu 2001), occupation (Fu 2008; ), and socioeconomic status (SES) (Schoen and Wooldredge 1989; Kalmijn 1998; Crowder and Tolnay 2000) have all been shown to be influential predictors of intermarriage. Education is widely known as a significant predictor of interracial marriages (Tucker and Mitchell-Kernan 1990; Qian 1997; Rosenfeld 2005; Gullickson 2006). Studies have consistently found that as the level of education increases, especially for racial minorities, the greater their likelihood of their intermarrying (Qian 1997; Fu 2001; Jacobs and Labov 2002; Qian and Lichter 2007). Age is another commonly used predictor variable in the intermarriage literature. It is widely accepted that younger individuals are more likely to intermarry than older individuals (Tucker and MitchellKernan 1990; Gullickson 2006; Rosenfeld 2007). Women were more likely to marry men older than themselves while men are more apt to marry women younger than themselves (Tucker and Mitchell-Kernan 1990; South 1991). Beyond education and age, military status (Jacobs and Labov 2002), whether a person is an immigrant (Qian and Lichter 2007; Hou and Myles 2013), and generational differences (Lichter, Carmult and Qian 2011) have been shown to be important individual-level predictors of intermarriage. 


\section{Structural Level Factors of Intermarriage}

While individual-level determinants are significant predictors of intermarriage, structural determinants are also crucial to consider when endeavoring to understand the trends of intermarriage in America. Blau's Inequality and Heterogeneity (1977) puts forth a macrosociological theory of human behavior and views social structure as "resting on a population's size distribution among different positions along various lines" (Blau et al 1982: 45). Contextual measures used in previous research analyses have varied: PUMA and metropolitan area (Campbell and Martin 2015), county level (Cready and Saenz 1997), metropolitan area level (Blau 1982 et al; Crowder and Tolnay 2000) and state level (Kalmijn and van Tubergen 2010). Relevant structural factors of intermarriage that have been employed include the sex ratio (Fossett and Kiecolt 1993;

Crowder and Tolnay 2000), relative minority size (Blau and Schwartz 1984; Blau, Blum, and Schwartz 1982; Hwang, Saenz, and Aguirre 1994; Cready and Saenz 1997), and racial heterogeneity (Blau and Schwartz 1984; Blau, Blum, and Schwartz 1982; Hwang, Saenz, and Aguirre 1994 Cready and Saenz 1997). Other structural level variables that have been used as predictors of intermarriage are the metropolitan status of an area (Cready and Saenz 1997), socioeconomic inequality and residential segregation (Blau et al 1824; Blau et al 1984; Blau and Schwartz 1984; South and Messner 1986). Racial heterogeneity refers to the number and size of various groups differentiated by race (Blau et al. 1982). Blau and his associates define heterogeneity as "the chance expectation that two randomly chosen persons belong to different groups" (Blau et al 1982: 47). With regard to intergroup contact, greater racial heterogeneity will 
result in more interracial contact, which should increase the probability of intermarriage. Lastly, "the concept of heterogeneity is most appropriate for a population comprised of more than two groups" (South and Messner 1986:1426). While Blau et al (1982) found a positive relationship between heterogeneity and intermarriage when income inequality was controlled, Cready and Saenz (1997) found a negative relationship and statistically insignificant effect between heterogeneity and intermarriage. Furthermore, Fitzpatrick and Hwang (1992) and South and Messner (1986) both conclude that while heterogeneity may be a proponent of promoting intermarriage rates within a community, it may also facilitate a decrease in intermarriage rates because of a built-in relationship between heterogeneity and minority group size.

Another structural variable of interest is relative minority group size. It is predicted to increase a person's odds of marrying an individual outside of their racial/ethnic group. In other words, Blau's macro-structural theory predicted an inverse relationship between group size and odds of intermarriage. Support for the relationship between group size and intermarriage was pretty consistent with respect to intermarriage among the various race groups, specifically, black-white intermarriage (Heer 1966; Heer 1977), Hispanic-white intermarriage (Monahan 1970; Monahan 1976).

While Blau and his associates did not specifically address sex ratio, it has also been used as a contextual variable in intermarriage research. Hwang and Saenz (1997) found that an increase in the sex ratio (meaning more men than women) decreased the likelihood of intermarriage among Asian women but increased intermarriage for Asian men. Cready and Saenz (1997) found a positive relationship between outmarriage and 
group-specific sex ratios for black men. This suggests that when an area has a high number of black males compared to black females, black males were more likely to marry outside of their racial group. For black women, they did not find a negative relationship, suggesting higher odds of outmarriage for women when black men are scarce in the area. To the contrary, they found no support and actually a significant positive relationship between the outmarriage of black women and group-specific sex ratios. They also found that outmarriage for black women was more likely when black men were relatively plentiful but could not provide an explanation for this finding. In this dissertation, I will attempt to provide a more nuanced explanation for the impact of group-specific sex ratios on the odds of intermarriage for black men and women.

\section{Structural Assimilation Theory: Educational Mobility}

In the third section of the literature review, I will provide an overview of structural assimilation theory and its relationship with intermarriage. Sociological studies of intermarriage suggest that individuals with higher levels of education are more likely to be involved in interracial romantic relationships Gordon 1964; Gullickson 2006; Lieberson and Waters 1988). Structural assimilation theory suggests that education and the education system's promotion of democratic and universalistic norms facilitates a break down of group barriers (Gullickson 2006; Kalmijn 1998; Lieberson 1988; Gordon 1964). By proxy of education, assimilation "influences intermarriage by affecting the extent to which a minority member is accessible and acceptable as a potential martial partner to members of the dominant group (Hwang et al., 1995; 472). 
Moreover, findings support the assumptions of structural assimilation theory that higher educated people often exhibit more acceptance of racial and ethnic groups which differ from their own (Hwang and Saenz 1997).

Beyond the education, there are more structural explanations for interracial marriage. For instance, Massey and Denton (1993) show that increased residential integration leads to more interracial contact, which may, in turn, result in higher chances of interracial romance. Also, attending college increases interracial contact as these populations tend to be more racially diverse than grade school (Yancey 2002). Overall, structural assimilation theory predicts a positive relationship between education and intermarriage.

\section{Merton's Status Exchange Theory}

The fourth section of my literature review covers Merton's status exchange theory. Robert K. Merton in 1941 developed his concept of status exchange when he analyzed the prevalence of interracial marriages between blacks and whites. He noticed that black men married across racial lines more frequently than did black women. His explanation for this gender differential was that black men of higher socioeconomic status could offer class status to lower socioeconomic status white women, whereas black women could not provide the same to white men given traditional gender roles concerning breadwinning (Merton 1941; Jacobs and Labov 2001). The early research supported Merton's theory primarily because black husbands were more often found to be upper class while their white wives were often found to be lower class (Van de 
Berghe 1960; Drake and Clayton 1945). Merton's status exchange theory became an innovative way to discuss racial and gender dynamics in marriage.

\section{Contemporary Scholars on Status Exchange}

Since Merton's presentation of his status exchange theory, there has been considerable debate on how well it describes black interracial marriage. Most discussions of status exchange theory only center on the use of individual-level characteristics. There is support both for and against the legitimacy of status exchange regarding its theoretical basis and its empirical testing (covered below in the methods section). Kalmijn $(1993,1996)$ and $\mathrm{Fu}(2001)$ all found support for status exchange theory by comparing the educational, racial, and gender differentials of spouses. Their studies found that white women more often than not experienced hypergamy or "married up" when their spouse was black, and this trend heavily favored black men more than it did black women, who were least likely to intermarry (Qian 1997; Jacob and Labov 2002). Fu (2001) found that black husbands of white wives had more education than black husbands of black wives. This was another study supporting status exchange theory. Also, this study found that white wives with black husbands had less education than white wives of white husbands, which led to the conclusion that not only status exchange theory is applicable in looking at interracial marriages, but that there is also a racial hierarchy that governs the marriage market (Fu 2001).

While there is much support for status exchange theory, there is also a group of scholars who hold there is not yet sufficient evidence of status exchange. Rosenfeld 
(2005) has been one of the biggest dissenters of status exchange theory with the assertion that status exchange is being mistaken for what is actually status homogamy. Rosenfeld (2005) has noted that simple tabulations give the actual story of black interracial marriages, which he believed is status homogamy. Rosenfeld insisted the reason tabular studies have been marginalized is based solely on their simplicity (Rosenfeld 2005). He explained that the complex models used by Kalmijn (1993) and Fu (2001) are not robust in terms of their findings. For instance, Rosenfeld (2005) asserted hypergamy was a four-way interaction (race* education for both spouses), but Qian's model did not control for the entire lower-order three-way model, which is needed to get a true measure of the four-way interaction (Rosenfeld 2005:1315). Rosenfeld also noted that each successive model he developed had added controls for the general patterns of education and intermarriage whereas Qian's models failed to do so. Furthermore, he argued that if researchers only chose the better fitting models and changed the assumptions or design of the models, their results would actually show no support for status exchange theory (Rosenfeld 2005:1319).

In response to the critiques by Kalmijn (2010) and Fu and Gullickson (2009) of his 2005 work, Rosenfeld retorted in a paper published in 2010 entitled "Still Weak Support for Status Exchange Theory;” that he still held firm to his position on status exchange theory. He argued that the use of log-linear models without appropriate controls hence lacking the best- fitting models to support their case shows that there is still weak support for status exchange. Rosenfeld used negative binomial regression models with appropriate controls along with replicated models of the other author's 
models to test for status exchange. He found weak support for the status exchange theory in black interracial marriage. Rosenfeld concluded that researchers should not abandon the best-fitting model to make their arguments, but researchers must focus on following the fundamental rules of selecting models that best fit the data. The context clearly needs to be included in the models for a more robust explanation.

Several studies addressed status exchange theory and the importance of contextual characteristics as they pertain to black intermarriage (Cready and Saenz 1997; Crowder and Tolnay 2000; Hou and Myles 2013; Gullickson and Torche 2014). While each of these studies found some support for status exchange theory for black men with white women when considering context, each disaggregated the contextual-level variables down to the individual which is very problematic for understanding the role of context on intermarriage. I present later a discussion why those approaches were problematic.

While there is an intense debate about the models that best analyze status exchange theory, what is missing is the proper statistical technique to do multilevel modeling when the context is considered. This void in the research is particularly important because Merton himself emphasized that mate selection includes context. Specifically, he noted that the interaction of context with individuals in a marriage market would help us better understand why status exchange theory is appropriate. My dissertation used the more statistically correct approach to the multilevel modeling of status exchange theory where contextual-level variables are not disaggregated to the individual level variables. My goal was to add an improved status exchange model and 
more specifically, to expand the understanding of how context impacts intermarriage patterns of African Americans.

\section{Setting the Context: Status Exchange is Beyond Individual Wants}

The fifth section of the literature review covers the modeling of context. In

general, scholars of status exchange theory (Qian 1997; Fu 2001; Rosenfeld 2005) have discussed the theory regarding individual-level determinants without giving serious consideration to structural factors. While individual level determinants are important, Merton himself identifies "structural constraints" and other euphemisms of context to be a critical part of the marriage market. In his seminal piece, "Intermarriage and Social Structure," Merton in 1941 asserted "rates of intermarriage are closely related to cultural orientation, standardized distributions of income and symbols of status" (217).

Furthermore, Merton speaks to the importance of context in mate selection, as follows:

The distinctions between norms and practices of mate selection are further necessary because practices are influenced not only by the rules but also by certain conditions [structural constraints] that facilitate or hinder conformity to the rules (220).

From Merton's work, therefore, an explanation for the occurrence of intermarriage in the U.S. should consider the context within the framework of status exchange. Merton goes a step further to discuss what type of population composition would be associated with rates of intermarriage: 
Among non-normative conditions affecting actual rates of in and outmarriage is group size, sex composition, age composition, and degree of contact between members of different groups" (221).

Again, the context was important given that these factors play a role in the event of marriage. Merton acknowledged "in no society is the selection of a marriage partner unregulated and indiscriminate" (Merton 1941: 217). Both individuals and "structural constraints" regulated marriage markets. Structural constraints for Merton included laws regulated marriage between particular racial groups, public and private establishments that dictated who could indulge in the services, or any space that facilitated the interaction of social groups because he understood that rates of intermarriage would be affected.

Merton clearly saw the mate selection process being facilitated by both individual wants and the surrounding environment, i.e., contexts, of the individuals. Hence the modeling of status exchange theory at a minimum should include contextual factors, specifically social structural constraints such as sex ratio and group size, in the mate selection process. This type of analysis requires the use of statistical techniques to model status exchange theory that will correctly incorporate two levels of analysis. Some of the past research using structural variables has not done this in a statistically correct way. My dissertation, in part, takes on the task of making the case that any study investigating status exchange theory must use hierarchical linear modeling analysis to capture what Merton was theoretically explaining in regards to interracial marriage in 
America.

\section{Issues Concerning Modeling Context}

The sixth and final section of the literature covers the issues of modeling context. Studies of intermarriage over the past 20-30 years have established the relationship between intermarriage and context. Many scholars have sought to understand how the properties of individuals are related to the properties of the environment in which the individuals are embedded. Many of these studies (Hwang, Saenz, and Aguirre 1994; Cready and Saenz 1997; Crowder and Tolnay 2000) disaggregated the context considerations down to the individuals. Others aggregated the individual-level characteristics up to the level of the contexts. I discuss briefly each approach (disaggregation and aggregation) and why each is not always the best way to model multilevel analysis.

The first approach I address is that of disaggregation. This method brings the contextual-level characteristics down (disaggregates them) to the individual level. So with regard to studying intermarriage, if we wanted to know the odds of intermarriage of black men in different cities, all of the characteristics of each city would be assigned to every black man living in the city, and the analysis would be conducted among individuals. The major problem here is that black men in the same city now have the same city characteristics, "thus [nullifying] the assumption of independence of observations that is basic for the use of classical statistical techniques" (de Leeuw, 1992: xiv). This means that since there is not a random assignment of black men to cities and 
since these men are nested into higher order groups, we would also need to adjust the standard errors in respect to individual level characteristics and the dependent variable. Baumle and Poston (2011) used a multilevel analysis to examine the economic costs of homosexuality. In their research, they illustrated how the disaggregation of contextual variables may result in different conclusions when compared with the results of analyses correctly using multilevel models in which the standard errors are of a more complex nature. The difference they noted between the two approaches led in some instances to differences in inferences. The level-1 results were similar. This was no surprise because under normal assumptions an OLS disaggregated estimation of a multilevel equation should be close that of a correct multilevel estimation of the same equation (Baumle and Poston 2011: 1031). The issue primarily deals with the assumptions of standard errors between the models: an OLS disaggregated model assumes no errors at level-2; a correctly estimated model does not make that assumption. Differences in error terms will lead to different inferences: they noted that three of their direct level-2 variables in the OLS multilevel model were negative but were found to have no effect in the correctly estimated model. Also, they showed different results for two of their cross-level interactions (Baumle and Poston 2011: 1031). Their work highlights the differences between each approach. So when we disaggregate contextual characteristics to individuals, we lose the assumption of independence and are prone to generating incorrect standard errors. Thus we should be cautious when selecting this approach to address multilevel modeling given that it ignores higher-level group differences.

Aggregation is the other method sometimes used in multilevel studies that should 
be avoided if at all possible. In this technique, individual level characteristics are aggregated up to the level of the context where the analysis is then conducted at level-2, among the contexts. In the case of the subject of this dissertation, we would bring the characteristics of the black men (i.e education and SES) up to the level of the city and conduct the analysis among the level-2 units, i.e., the cities. The main problem here is that we discard all of the within-city variation which could mean that we lose as much as 80-90 percent of the variation before we even begin the analysis (Raudenbush and Bryk, 2002). Moreover, information is wasted and interpretation of the results could be compromised were we to interpret the aggregate relationships at the individual level. The seminal work of W.S. Robinson (1950), "Ecological Correlations and the Behavior of Individuals" illustrates how a strong association between two aggregate variables cannot be taken as evidence of a causal link at the individual level. His work used illiteracy rates and immigration rates to bring the point home: a negative correlation between these two aggregate level characteristics does not mean that immigrants have higher rates of literacy than U.S. citizens. He found that the individual level correlation was positive but given that immigrants settle in high literacy states, this actually contributed to the negative correlation among the aggregate characteristics. His analysis led to the term, the "ecological fallacy," referring to the situation in which the researcher assumes that an individual level relationship can always be derived from a correlation between aggregates. Aggregation, as we can see, is not an appropriate approach to multilevel modeling given that it ignores lower level individual differences.

In this literature review, I have provided an overview of important issues in 
respect to my dissertation. I have presented a general overview of intermarriage in the United States, and I have reviewed individual and structural determinants of intermarriage. I have defined status exchange theory and educational mobility and how each predicts levels of education for interracially marrying couples. I have discussed Merton's work on context; I have noted several issues with modeling context. Merton's status exchange theory is theoretically relevant to contemporary discussions about how marriage is facilitated in part by the race, gender and class characteristics of the individual. Educational mobility suggests that as people achieve higher levels of education, they are more likely to intermarry. Merton's personal conceptualization is necessary for how contemporary scholars model status exchange theory in that the analyses should include both individual and contextual level variables. Moreover, when including these two levels of analyses, researchers should be aware of the approaches used to deal with multilevel models. Neither disaggregation nor aggregation was the preferred approach. The former foregoes the assumption of independence given that all contextual-level variables are now modeled at the individual level while the latter runs the risk of losing a good amount of the variation because the individual level variables are aggregated to the context for analysis.

I move now to the third chapter of the dissertation. In this chapter, I will discuss in detail the data and methods to be used in my analyses. 


\section{CHAPTER III}

\section{DATA AND METHODS}

In this chapter, I discuss in some detail the data and the methods I will use to analyze black intermarriage. I first review the data.

\section{Data, Sample, and Sample Restrictions}

I extracted the individual-level data used in this dissertation from the American Community Survey, 1 percent samples from 2008 through 2014. I accessed these data via the Integrated Public Use Microdata Sample (IPUMS) system of the University of Minnesota. The data pertain to individuals and households. My dependent variable is whether or not the black man (or woman) intermarries. Logistic regression was the most appropriate method of analysis for a binary dependent variable (i.e. predicting whether a black spouse is intermarried or not and I describe it later in this chapter. I present descriptive tables with selected variables and their definitions below.

Also, in this section, I discuss the contextual-level data I use in the dissertation. These data were obtained from the 2005 and 2013 American Community Survey (ACS) and were gathered for a selected number of Metropolitan Statistical Areas (geographic areas containing at least 500,000 or more persons) located within the United States. Contextual level variables are sex-specific group size, racial heterogeneity, and the sex ratio. These predictors are used along with the primary individual level variables in the multilevel analysis. This method was the most statistically appropriate way to examine 
the effects of contexts, i.e. MSA characteristics, on the log odds of black intermarriage. I now provide more detail about the ACS data, the methodology, and the data used at the contextual level.

\section{Individual Level Data}

This dissertation analyzed two dichotomous dependent variables for black men and women residing in U.S. metropolitan areas: intermarriage among black men and intermarriage among black women. For both black men and women, intermarriage is a dummy variable scored " 1 " if an individual's spouse was of a different race; it is scored "0" if their spouse was of the same race. This analysis was restricted to non-Hispanic whites and non-Hispanic blacks; all other racial and ethnic groups were dropped from the sample. The data pertaining to each married couple that was linked by a spouse variable with demographic variables. This sample was restricted more to those in first marriages formed within the past twelve months.

The data analyzed at the individual are derived from the 2008-2014 American Community Survey (ACS), as provided in the Integrated Public Microdata Series (IPUMS), Version 6.0, made available by the Minnesota Population Center. The ACS is an annual national survey given to approximately three million U.S. households to "provide estimates of demographic, housing, social, and economic characteristics every year for all states, as well as for all cities, counties, metropolitan areas, and population groups of 65,000 people or more" (Ruggles et. al 2015). It serves to replace the decennial census long form that provided detailed information on population and 
housing characteristics. While the long form provided data once every ten years on population and housing characteristics, the ACS conducts monthly surveys that are compiled on a yearly basis. Thus, it could be argued that an advantage the ACS has over the long form is that is based on a (relatively) continuous measurement and provides more accurate and time-sensitive estimates (Ruggles et. al 2015).

As just noted, the data used for the individual level analyses in my dissertation are based on a nationally representative sample of the United States and were extracted from the Census Bureau's ACS 1\% IPUMS samples from 2008 to 2014. The data were extracted using the IPUMS online data extraction system where data users can select subsets of samples and variables for their research (Ruggles et. al 2015). Researchers refer to these data as "Microdata" since they provide information on persons and households.

Each of the ACS data samples from 2008-2014 is based on a 1 in 100 national sample of the population. The data are weighted, and data users must weigh their cases accordingly through the use of statistical analysis software to produce precise estimates (further discussion of weighting below) (Ruggles et. al 2015).

The ACS sample from 2008-2014 contained 13,322,659 household and $21,583,529$ person records. The lowest level of geography is the Public Use Microdata Area (PUMA), which contains a minimum of 100,000 persons. The metropolitan area (MET2013) variable in IPUMS is the variable used to identify each of the 366 metropolitan areas in the United States. The metropolitan area has been used in previous research to model marriage markets (Blau and Schwartz 1984; Fossett and Kiecolt 
1993). Once extracted, my sample was reduced to MSAs with at least 20 married black men and women to make gender comparisons across the same MSAs; this left me with 27 MSAs. To have reliable estimates, there must be variation among the marriages types in each of the MSAs. Thus any MSAs with zero interracial couples were dropped. This left 26 MSAs for black men and 24 MSAs for black women for analysis. I provide below tables with frequency counts of the number of married black men and black women in each of the MSAs (see Tables 3.1 and 3.2.) With these restrictions implemented, I have 3,219 total couples: 2,926 black-black couples, 81 black-female-white male couples, and 212 black male-white female couples. 


\begin{tabular}{|l|l|l|}
\hline \multicolumn{3}{|l|}{ Table 3-1. Married Black Men in Metropolitan Statistical Areas, 2008-2014. } \\
\hline Metro Area with 500,000+ & $\begin{array}{l}\text { Black Men Married to Black } \\
\text { Women }\end{array}$ & $\begin{array}{l}\text { Black Men Married to White } \\
\text { Men }\end{array}$ \\
\hline Atlanta, GA & 164 & 11 \\
\hline Baltimore, MD & 65 & 8 \\
\hline Baton Rouge, LA & 21 & 1 \\
\hline Birmingham, AL & 38 & 2 \\
\hline Charlotte, NC & 46 & 10 \\
\hline Chicago, IL & 97 & 13 \\
\hline Cleveland OH & 28 & 10 \\
\hline Dallas-Fort Worth, TX & 74 & 18 \\
\hline Detroit, MI & 55 & 8 \\
\hline Greensboro, NC & 46 & 1 \\
\hline Houston, TX & 97 & 7 \\
\hline Indianapolis, IN & 29 & 4 \\
\hline Jackson, MS & 28 & 1 \\
\hline Jacksonville, FL & 28 & 3 \\
\hline Los Angeles, CA & 42 & 14 \\
\hline Memphis. TN & 54 & 2 \\
\hline Miami, FL & 49 & 8 \\
\hline Nashville, TN & 25 & 7 \\
\hline New Orleans, LA & 38 & 3 \\
\hline New York-Newark, NY/NJ & 113 & 14 \\
\hline Philadelphia-Camden PA/NJ & 71 & 17 \\
\hline St. Louis, MO/IL & & \\
\hline Shreveport, LA & 36 & 4 \\
\hline Tampa, FL & 21 & 8 \\
\hline Virginia Beach-Newport, VA & 26 & 10 \\
\hline Washington-Arlington, & 108 & 9 \\
\hline DC/VA & & \\
\hline & & \\
\hline
\end{tabular}




\begin{tabular}{|l|l|l|}
\hline \multicolumn{3}{|l|}{ Table 3-2. Married Black Women in Metropolitan Statistical Areas, 2008-2014. } \\
\hline Metro Area with 500,000+ & $\begin{array}{l}\text { Black Women Married to } \\
\text { Black Men }\end{array}$ & $\begin{array}{l}\text { Black Women Married to } \\
\text { White Men }\end{array}$ \\
\hline Atlanta, GA & 164 & 4 \\
\hline Baltimore, MD & 65 & 6 \\
\hline Baton Rouge, LA & 21 & 1 \\
\hline Birmingham, AL & 38 & 1 \\
\hline Charlotte, NC & 46 & 2 \\
\hline Chicago, IL & 97 & 5 \\
\hline Cleveland OH & 28 & 4 \\
\hline Dallas-Fort Worth, TX & 74 & 4 \\
\hline Detroit, MI & 55 & 1 \\
\hline Houston, TX & 97 & 3 \\
\hline Indianapolis, IN & 29 & 1 \\
\hline Jacksonville, FL & 28 & 2 \\
\hline Los Angeles, CA & 42 & 6 \\
\hline Memphis. TN & 54 & 2 \\
\hline Miami, FL & 49 & 2 \\
\hline Nashville, TN & 25 & 1 \\
\hline New Orleans, LA & 38 & 3 \\
\hline New York-Newark, NY/NJ & 113 & 7 \\
\hline $\begin{array}{l}\text { Philadelphia-Camden } \\
\text { PA/NJ }\end{array}$ & 71 & 5 \\
\hline St. Louis, MO/IL & 36 & 2 \\
\hline Shreveport, LA & 21 & 1 \\
\hline Tampa, FL & 26 & 4 \\
\hline Virginia Beach-Newport, & 66 & \\
VA & & \\
\hline $\begin{array}{l}\text { Washington-Arlington, } \\
\text { DC/VA }\end{array}$ & 108 & \\
\hline & & 2 \\
\hline
\end{tabular}




\section{Issues with Data}

Generally, with prevalence data, Qian and Lichter (2011) have noted that we are subjected to biased estimates of marriage incidence because there tend to be marriage disruption differences by marriage duration especially if marriage separation differs between interracially and same-race marriages (Qian and Lichter 2011:1070). Here, I endeavor to circumvent this potential selection bias by using incidence data on new marriages identified in the 2008-2014 ACS, which approximates actual incidence data from vital registrations (Qian and Lichter 2011). Also, to build a case for and to test for the importance of context, this study used measures of racial heterogeneity, sex-specific group size, and sex ratio.

The weighting of the samples in the ACS is an issue I will now address. Many of the sample weights are unweighted which indicates to data users that each case in the sample represents a single case in the population. For the ACS, it is necessary to use weighted samples given that certain people are either overrepresented or underrepresented in the sample (Ruggles et 2015). Using sample weights in the ACS provides reliable and statistically accurate estimates of the population (ACS 2003). Weighting the sample reflects sample design, adjusts for non-responders, and corrects for the survey under coverage (ACS 2003). If data users want representative statistics of the U.S general population, they must apply the sample weights (Ruggles et al. 2015; ACS 2003).

There are two types of weights the data user can select from to implement the proper weighting of their samples: 1) person weight (PERWT), and 2) household weight 
(HHWT). Given that I am interesting in the black spouse of these married couples because that is where the analysis is centered, PERWT (the variable used in the weighting calculation) is the appropriate choice as it gives the number of persons

represented in the general population by each person in the sample (Ruggles et. al 2015). The weighting scheme resembles that of the original structure introduced by the Census Bureau. The "svy" commands in STATA were used to weight each person.

\section{Method}

This research utilizes multilevel binary logistic regression where the race of spouse is the dependent variable, thus indicating whether the marriage is interracial or not. Specifically, to address the odds of intermarriage in a binary dependent model, I estimated the log odds of black males being intermarried to a spouse of a different race versus being married to a spouse of the same race, and I did the same for black women. Separate analyses were conducted for black men and black women to better understand the gender differentials within black intermarriage.

\section{Logistic Regression}

Logistic regression assesses the probability that an individual is interracially married rather than intraracially married. This dependent variable is predicted with a set of micro-level independent variables and macro-level independent variables. Logistic regression has been used in many studies looking at interracial marriage (MitchellKernan 1990, Qian 1997, Jacobs and Labov 2002). With logistic regression, the 
predicted probability is within the bounds of one and zero (Long and Freese 2015).

Education of the spouse served as the key micro-level predictor. I hypothesized that the predicted probability of a black person intermarrying should increase their level of education increase. The variable for education is coded on an 8-point scale ranging from "No school" to "Professional/Doctoral degree." I treated the educational categories as interval, which was appropriate for most of the educational outcomes.

The education gap variable is the main indicator of Merton's status exchange theory. It measures whether status exchange is occurring for the black spouse. This variable is used to test the status exchange hypothesis. I calculated it by subtracting the black spouse's education from that of their spouse. Given that the education variable is coded on an 8-point scale, there will be cases of a negative score when a man or woman has a greater education than that of the spouse.

Age is a continuous variable introduced into the level one analysis as a control variable. Previous studies have found that age variations in intermarriages are frequent (Hwang, Saenz. Aguirre 1997; Lieberson and Waters 1988).

Beyond the couple-level analysis, my dissertation aims to "reintroduce the importance of context" in an examination of black intermarriages. Anderson and Sellers have written that "[a] context is simply the background, or environs, relevant to a particular event...[t]hus contextual effects refer to the influences of context characteristics on individuals or the events experienced by individuals" (Anderton and Sellers 1989). Previous intermarriage work has used log-linear analysis (Qian 1997; Qian and Lichter 2007; Gullickson 2006), and logistic regression (Jacobs and Labov 
2002; Tucker and Mitchell-Kernan 1990). Several other studies have considered both individual-level and contextual-level variables in their models were predicting intermarriage but usually disaggregated the contexts down to the individual level. In my dissertation, I am using correctly estimated multilevel models to predict the log odds of intermarriage for both black men and women. No previous study, as far as I am aware, has used this method in a study of black intermarriage.

\section{Introduction to Multilevel Modeling}

Sociologists know it is paramount to understand how both individual and context help facilitate behavior at the individual level. Structural assimilation implies a multilevel understanding of the incidence of marriage. Status exchange theory articulates marriage formation as a multilevel process whereby marriage is impacted by not only the characteristics of the individual but also the surrounding environment around the person. Thus, in this dissertation, I undertake a two-level analysis that will look at the effects of MSA contexts along with person characteristics on the individual level (i.e. the likelihood of intermarriage). The primary individual level variables are education and the spousal education gap; the MSA contextual-level variables are the sex ratio, sexspecific group size, and racial heterogeneity.

One of the primary purposes for using multilevel modeling is to illustrate the importance of structural determinants of intermarriage. I hope to show how intermarriage is impacted not only by individual level variables and by contextual variables, but also indirectly via cross-level interactions. Such analyses will demonstrate 
how individual-level, and contextual level determinants are associated with intermarriage among U.S. black men and women.

Multilevel analysis allows the researcher to isolate the effects of the individual level variables on the outcome, as well as the effects of the contextual-level variables. The model thus allows for the incorporation of both the individual level and contextuallevel variables in the analysis. Only including a contextual level variable in an individual level model does not satisfy the status exchange theory framework which suggests that context is independent of individual level variables. DiPrete and Forristal (1994) have written about this function of multilevel modeling, as follows:

Multi-level models explain micro-level outcomes in two ways: (i) by showing that parameters of models specified at the micro level - where micro level covariates are used to describe micro-level outcomes - are a function of context, and (ii) by showing that this micro-macro relationship can be expressed in terms of characteristics of the context, which take the form of macro-level variables (DiPrete and Forristal 1994: 333).

Multilevel models are used to understand the effect of contextual-level characteristics, i.e., characteristics of the PUMA, on individual level outcomes (Garcia 2008: 76).

Multilevel modeling allows us to understand better how status exchange theory influences the likelihood of black intermarriage. Figure 1, reprinted from Anderton and Sellers (1989), below is an example of a contextual model where we can see three types of effects on the individual outcome. As already noted many times, in this dissertation the individual outcome is intermarriage; the " $\mathrm{b}$ " effects are level-1 or individual level direct effects on the outcome; the "G" effects are level-2 direct effects on the outcome; and the "g" effects are cross-level interactions of level-2 variables on the slopes of level- 
1 variables. I present a particular contextual model as an example in the next section.

FIGURE 1. Contextual-Effects Model

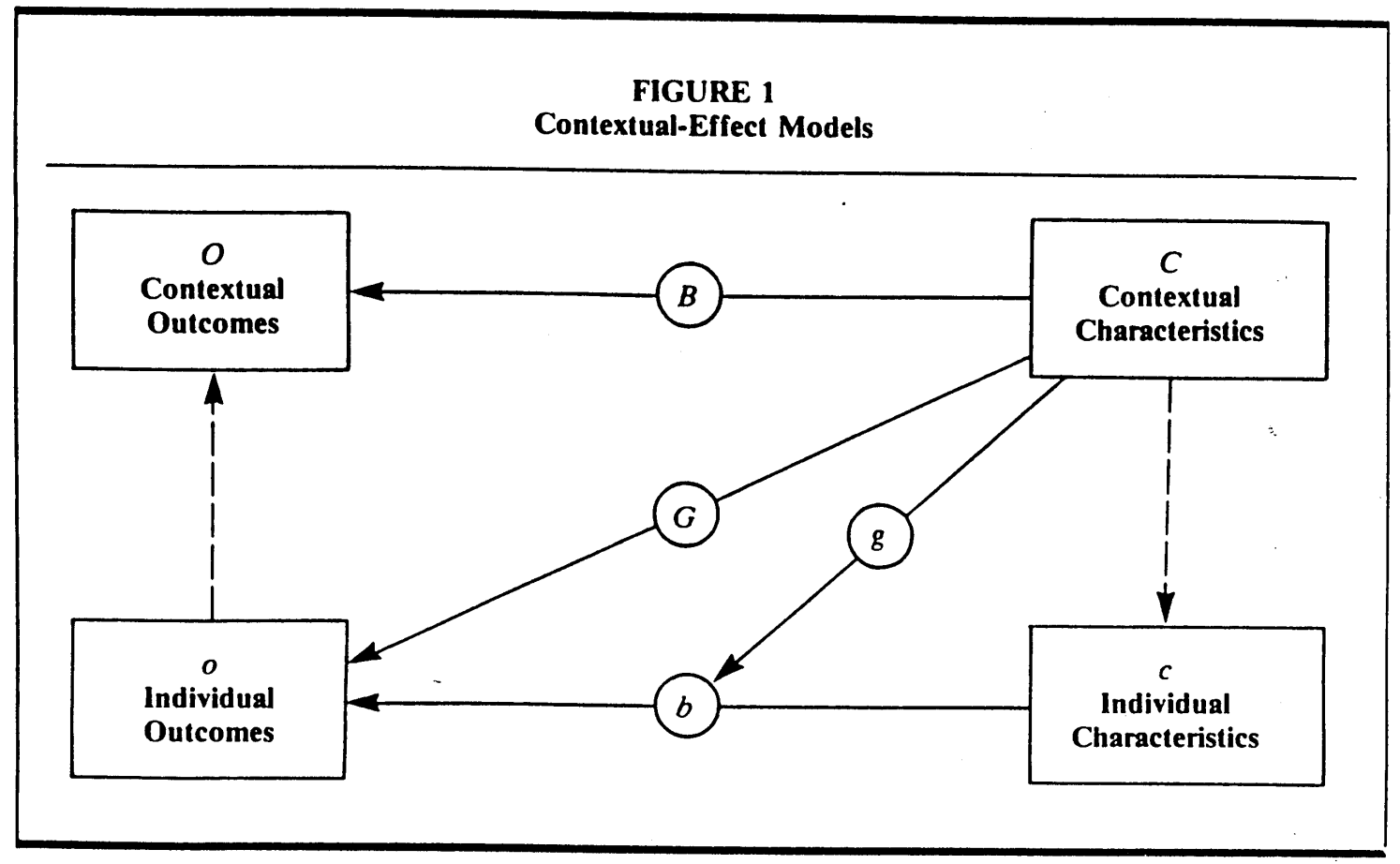

Reprinted from: Anderton and Sellers, 1989: page 107

The contextual factors I will use are group size, the sex ratio, and racial heterogeneity (the M6 index of Gibbs and Poston, 1975), all of which have been used previously as indicators of context on marital choices (Fossett and Kiecolt 1993; Cready and Saenz 1997; Hwang, Saenz and Aguirre 1997). Previous research identified each of these as a structural factor influencing the odds of intermarriage (Blau and Blum 1982; Cready and Saenz 1997; Hou and Myles 2013). I turn next to the operationalization of the context variables.

The sex ratio of an MSA is the number of unmarried African-American men per 
100 unmarried African-American women in the MSA. The men and women captured in the sex ratio will be restricted to persons ranging in age from 20 to 45 .

The sex-specific group size variable, one for men and one for women, is the proportion of African-Americans men and women ages 20-45 to all groups in each MSA.

The racial heterogeneity variable is the M6 index developed by Gibbs and Poston (1975) with the categories being the number of African-Americans, Latinos, whites and Asians in each MSA.

I introduced a control at the contextual level for region. It was dummy coded as "South" with either a "Yes" or "No" indicating whether the persons were or were living in the South. Since I require the marriages to have occurred in the past year, it is somewhat likely that the region variable will indicate where the marriages were contracted. I controlled for region "due to the chances that [racial minorities] may live in an area of the country where their group is less likely to out-marry, regardless of age and education" (Cready and Saenz 1997).

\section{Issues Concerning Modeling Context}

Several studies of intermarriage over the past 20-30 years have established the relationship between intermarriage and context. Specifically, scholars have sought to understand how the properties of individuals are related to the properties of the environment in which the individuals are embedded. Many of these studies (Hwang, Saenz, and Aguirre 1994; Cready and Saenz 1997; Crowder and Tolnay 2000) accounted 
for context by disaggregating the context variables down to the level of the individuals and then estimated micro-level equations were predicting intermarriage. Some other analyses introduced context by aggregating all the micro-level variables up to the level of the context, e.g., the metropolitan area or the state, and then estimating a single statelevel or metro-level equation. Raudenbush and Bryk (2002), among others, have noted that both approaches are statistically incorrect techniques. I discuss briefly each approach (disaggregation and aggregation) below and how neither is appropriate for multilevel analyses.

The first approach I address is that of disaggregation. This approach brings down (disaggregates) the contextual-level variables down to the individual level. So on studying intermarriage, if we wanted to know the odds of intermarriage of black men in different cities, all of the characteristics of the city would be assigned to every black man depending on his city of residence, and the analysis would be conducted only at the individual level. The biggest problem here is that black men in the same city now all have the same city characteristics, "thus [nullifying] the assumption of independence of observations that is basic for the use of classical statistical techniques" (de Leeuw, 1992: xiv). But black men (or women) are not independent observations in each MSA; that is, there is not a random assignment of black men to cities. But since these men are nested into higher order groups, we need to adjust the standard errors in respect to individual level characteristics and the dependent variable. To make this point, Baumle and Poston (2011) used multilevel analyses in their research on the economic costs of homosexuality. In their research, they illustrated how the results from a model in which 
they disaggregated the contextual variables led to some different inferences compared to the results from a model they estimated using a correct multi-level approach. The difference they note between the two approaches leads to differences in conclusions. The results of most of the level-1 variables were similar between the two models. The major differences had to do with the results of the level-2 variables; this occurred because the OLS disaggregated model assumed no error was occurring at level-2. The correctly estimate multi-level model does not make that assumption; the error term is much more complex at level-1 and level-2. So when we disaggregate contextual characteristics to individuals, we lose the assumption of independence and are prone to incorrect standard errors (downward bias).

Aggregation is the other approach used in multilevel studies that have statistical problems. In this technique, individual level characteristics are aggregated up to the level of the context where the analysis is conducted. If I were to follow this approach, I would average the characteristics of the black men (i.e., education and age and so forth) up to the level of the MSA and then conduct an analysis among the MSAs. The main problem here is that we will discard all of the within-city variation which could mean that we lose as much as $80-90$ percent of the variation before we even begin the analysis (Raudenbush and Bryk, 2002). Information is wasted and, moreover, interpretation of the results is compromised if we use the aggregate relationships to make inferences at the individual level. Aggregation is not an appropriate approach to multilevel modeling because it ignores lower level individual differences. 


\section{Summary}

In chapter three, I have provided an overview of the data used in this dissertation, the statistical method employed, a description of the marriage data in each MSA, operationalization of each variable, and an introduction to multilevel modeling. Chapter four will cover the level one analysis for both intermarried black men and black women. 


\section{CHAPTER IV}

\section{LEVEL ONE ANALYSES}

In this chapter, I examine the extent to which both educational mobility theory (also referred to as structural assimilation theory) and status exchange theory assist us in understanding the likelihood of black men and black women marrying non-black spouses. I will accomplish this objective by estimating logistic regression models. In the sections below I first outline the hypotheses associated with each theory and operationalize the variables used in the respective logistic models. Next, I provide a statistical description of the dependent variable and the independent variables for the black men and black women in my metropolitan samples. Third, I provide a discussion of the diagnostic procedures I used to evaluate the statistical adequacy of each model. Finally, I present and discuss the results of the logistic regression equations. I am most interested in ascertaining which, if any, of the education-based models, works best in predicting the log odds of intermarriage of black men and women. And I will determine whether these effects the same or different for males compared to females.

\section{Hypotheses and Operationalization}

I will first test for the hypothesized effect of educational mobility on racial intermarriage (Hypothesis 1 and Hypothesis 2 for black men and women, respectively). Structural assimilation theory stipulates that the higher the educational level of black men (or black women), the greater their likelihood to engage in an interracial marriage. I 
use the educational level of the black men (and the black women) as the key independent variable in these hypotheses.

Hypothesis 1: The greater the level of education of black men, the greater the likelihood of their racial intermarriage

Hypothesis 2: The greater the level of education of black women, the greater the likelihood of their racial intermarriage

The education variable here is a 22-point scale from "No education" is indicated with " 0 years of education" to "Professional Degree/Ph.D." which is indicated by "22 years of education". If educational mobility is correct, then for both black men and women, as their level of education increases so will their odds of intermarriage to whites. Age is entered as a control variable because younger individuals are more likely to intermarry than older persons.

Status exchange theory is examined in Hypothesis 3 and Hypothesis 4 for black men and black women, respectively. Proponents of status exchange argue that the greater the difference between the SES of the black men and his spouse, the greater the likelihood the black man will be in an interracial marriage. The educational disparity argument is not expected to be supported when examining whether black women are in interracial marriages (Gullickson 2006; Hou and Myles 2013). So I am hypothesizing the following

Hypothesis 3: The greater the education disparity of black men compared to their spouses, the greater the likelihood of the black men being in interracial marriages.

Hypothesis 4: There is not expected to be an association between the level of educational disparity between black women and their spouses and the likelihood of the women being in interracial marriages. 
The education gap variable is the absolute value of the difference of the black man's or black woman's education level from the spouse's education level. If status exchange is operable, the education gap variable coefficient will be positive and significant only in the equation for black men. Again, age is controlled for because younger individuals are more likely to intermarry.

\section{Descriptive Statistics}

I now present means and other descriptive statistics for the black men and black women in my metropolitan area samples of the United States (see Tables 4-1 and 4-2 below). The samples for both black men and women were restricted to non-Hispanic black spouses who are in their first marriage that was contracted within the past year of when the survey was taken, and resided in a metropolitan area. Further, black men and women residing in metropolitan areas containing less than 20 sample cases were excluded. This was done to maintain consistency with the multi-level analyses to be presented in Chapter 5, which require at least 20 cases per metropolitan area.

The sample for black men (Table 4-1) is comprised of 1,675 cases $(250,299$ weighted) while the sample for black women (Table 4-2), 1,544 cases $(216,569$ weighted). Minimum and maximum values of both the dependent and independent variables are presented in the tables. As indicated above, intermarriage was coded as a dichotomous variable, scored 1 if the black spouse was intermarried and 0 if not. The mean of intermarriage for black men was 0.123 and the mean for black women was 
0.052. This means that just over 12 percent of the black men have white wives while over 5 percent of the black women have white husbands.

\begin{tabular}{|c|c|c|c|c|}
\hline $\begin{array}{l}\text { Dependent } \\
\text { Variable }\end{array}$ & Minimum & Maximum & Mean & $\begin{array}{l}\text { Standard } \\
\text { Deviation }\end{array}$ \\
\hline $\begin{array}{l}\text { Intermarriage } \\
(1=\text { yes, } 0=\text { no })\end{array}$ & 0 & 1 & 0.123 & 0.328 \\
\hline $\begin{array}{l}\text { Independent } \\
\text { Variables }\end{array}$ & Minimum & Maximum & Mean & $\begin{array}{l}\text { Standard } \\
\text { Deviation }\end{array}$ \\
\hline $\begin{array}{l}\text { Educational } \\
\text { Attainment }\end{array}$ & 0 & 22 & 13.311 & 2.354 \\
\hline Educational Gap & 0 & 14 & 1.641 & 1.947 \\
\hline Age & 20 & 45 & 30.421 & 5.69 \\
\hline
\end{tabular}

Table 4-2. Descriptive Statistics, 1,544 Black Women Residing in Metropolitan Statistical Areas, 2008-2014.

\begin{tabular}{|l|l|l|l|l|}
\hline $\begin{array}{l}\text { Dependent } \\
\text { Variable }\end{array}$ & Minimum & Maximum & Mean & $\begin{array}{l}\text { Standard } \\
\text { Deviation }\end{array}$ \\
\hline $\begin{array}{l}\text { Intermarriage } \\
(1=\text { yes, } 0=\text { no })\end{array}$ & 0 & 1 & 0.052 & 0.222 \\
\hline $\begin{array}{l}\text { Independent } \\
\text { Variables }\end{array}$ & Minimum & Maximum & Mean & $\begin{array}{l}\text { Standard } \\
\text { Deviation }\end{array}$ \\
\hline $\begin{array}{l}\text { Educational } \\
\text { Attainment }\end{array}$ & 0 & 22 & 13.828 & 2.517 \\
\hline Educational Gap & 0 & 14 & 1.608 & 1.938 \\
\hline Age & 20 & 45 & 29.2 & 5.400 \\
\hline
\end{tabular}

The independent variable of education attainment of the black spouse, ranges from 0 years, which indicates no schooling, to 22 years which indicates a professional degree or doctorate. The mean for the black men is 13.3 years, noting that on average they have some college. The mean value for black women is slightly higher, at 13.8 years. 
The independent variable representing the education gap among spouses is the absolute value of the difference of the black spouse's education from his spouse's education. These values range from 0 years difference, which indicates the spouses have the same level of education to 14 years difference, which shows that the spouse, has 14 more years of education. The mean education gap for black men was 1.64 years, while it was 1.62 years for black women. The absolute value of the education gap between black husbands and their wives on average are necessarily equal to black wives with their husbands. This is an interesting descriptive statistic because I expected the disparity to be greater for black men than for black women. In the next section, I discuss the various diagnostics undertaken before estimating the regression equations.

\section{Logistic Regression Diagnostics}

Diagnostics were calculated for each of the four individual-level models discussed above, i.e., two for metropolitan black men and two for metropolitan black women). In the paragraphs below, I address the diagnostics for each model.

Model 1 examined the effect of educational attainment on interracial marriage for black men. The first model focused on structural assimilation theory for black men and included one primary independent variable, educational attainment of the black husband. I first examined the degree of multicollinearity among the three $\mathrm{X}$ variables, education, and two age variables. Model 1 had a tolerance value of .99 for the primary independent variable, male years of education. Male age and female age variables in Model 1 both had tolerance values of .47 . These are acceptable tolerances suggesting that the model 
does not have problematic amounts of multicollinearity. For the remaining three models, the tolerances were again assessed for the independent variables in each model. None of the tolerances were under 0.45 , suggesting that in all the estimated models there were no major issues of multicollinearity.

After estimating each model, there was no statistical need to assess the prevalence of non-normal error distributions, as would have the situation had I been estimating ordinary least squares (OLS) models. In a logit model, it is not assumed that the errors are normally distributed; indeed the distributional assumptions underlying OLS regression models do not apply regarding logistic regression models. However, Osborne (2015: 100) reminds us that "it is sometimes the case that highly non-normal independent variables can distort parameter estimates ... because they contain highly influential outliers, rather than the non-normality itself ..." Hence I examined the skewness and kurtosis values for the independent variables in my four models. None of my independent variables had problematic skewness or kurtosis values, with one exception: the educational gap independent variable, for both males and females, had skewness values around twice the magnitude of the rule-of-thumb "value of concern" of +/- 0.8 (Lewis-Beck 1995: 16). I thus transformed the educational gap variable by taking its natural log. I then re-estimated the black male and the black female equations using the transformed educational gap variable instead of the raw, untransformed educational gap variable. The effects of the untransformed and transformed educational gap variable on the log odds of intermarriage hardly differed in magnitude, and the statistical 
inferences were the same. I thus opted to use the untransformed educational gap variable in the logit equations reported below.

\section{Logistic Regression Results}

Model 1 (Table 4-3), which tested structural assimilation theory among black husbands, affirms that as their educational attainment increased, so did their odds of intermarriage. As discussed earlier, structural assimilation theory suggests that people with higher levels of education are more likely to intermarry. There was a significant and positive effect in Model 1 lending support for the first hypothesis concerning educational mobility. For each one-year increase in the level of education, the odds of being intermarried increase by 13 percent, other things equal.

\begin{tabular}{|c|c|c|c|c|}
\hline \multicolumn{5}{|c|}{$\begin{array}{l}\text { Table 4-3. Logistic Regression Results: Educational Mobility for Black Husbands in } \\
\text { Metropolitan Statistical Areas. } \\
\text { N=250, } 299 \text { (Weighted) }\end{array}$} \\
\hline Model 1 & Odds Ratio & $\begin{array}{l}\mathrm{b} \\
\text { Linearized SE }\end{array}$ & $\mathrm{t}, \mathrm{p}>0$ & Tolerance \\
\hline $\begin{array}{l}\text { Husband's } \\
\text { Education }\end{array}$ & $1.127^{*}$ & $\begin{array}{l}0.120 \\
0.035\end{array}$ & $3.40,0.001$ & 0.99 \\
\hline Husband's Age & 1.046 & $\begin{array}{l}0.045 \\
0.024\end{array}$ & $1.87,0.062$ & 0.47 \\
\hline Wife's Age & 0.924 & $\begin{array}{l}-0.082 \\
0.025\end{array}$ & $-3.26,0.001$ & 0.47 \\
\hline Constant & 0.051 & $\begin{array}{l}-2.76 \\
0.680\end{array}$ & $-4.06,0.000$ & \\
\hline
\end{tabular}


Model 2 (Table 4-4) provides very similar results for black women. For every year increase in the educational attainment of black women, there is about a 14 percent increase in their odds of intermarrying, ceteris paribus.

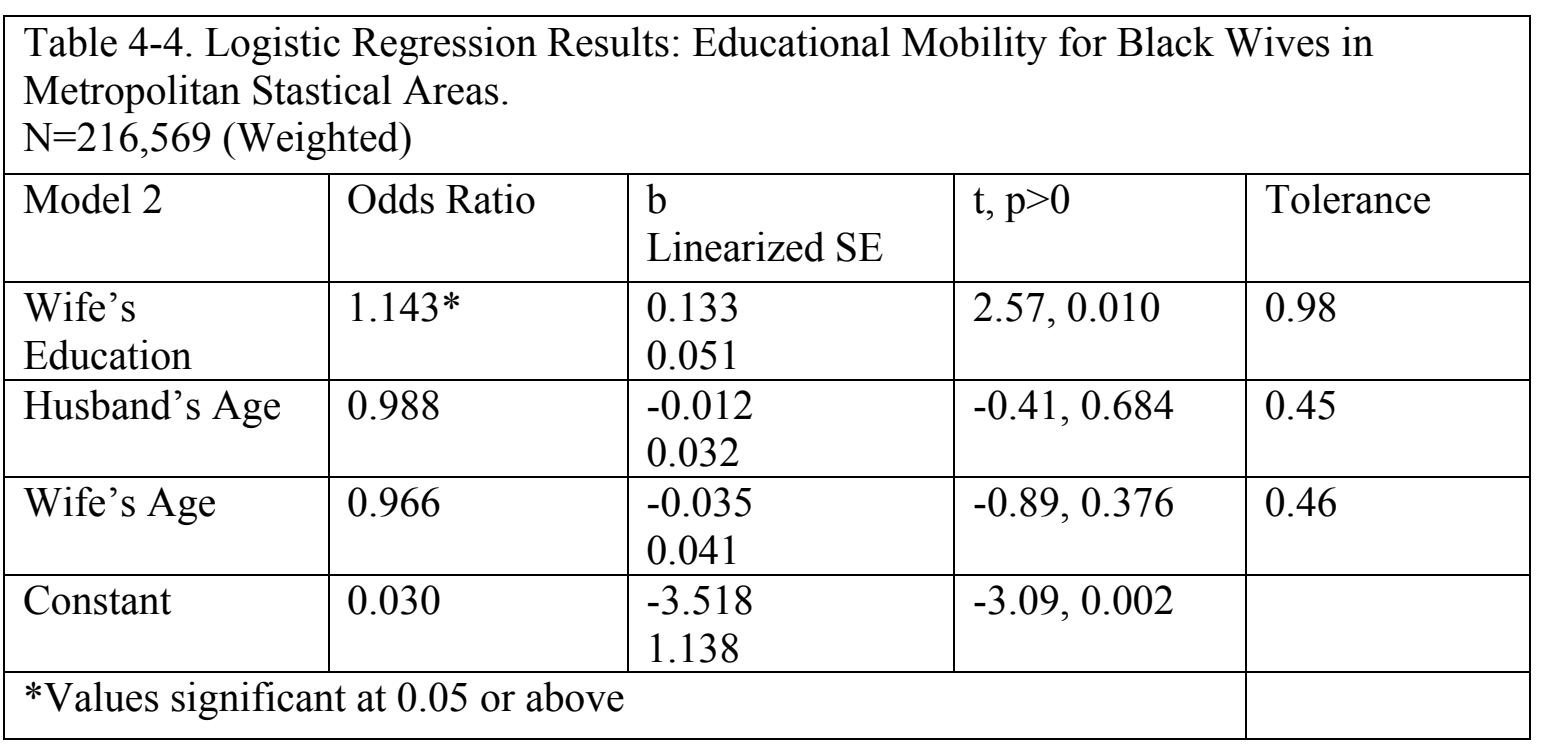

Model 3 (Table 4-5) assessed status exchange among black husbands. Recall that status exchange theory asserts that intermarriage occurs between high-status blacks and low-status whites (particularly among black men who marry white women). My third hypothesis asserts that as the education disparity between the black husband and the spouse increases so does the odds of intermarriage. Model 3 supported my third hypothesis; the effect of the education disparity gap is positive and statistically significant. Specifically, for each additional year increase in the education gap between the black husband and his wife, the odds of intermarriage increases by 13 percent, all else equal. 


\begin{tabular}{|c|c|c|c|c|}
\hline Model 3 & Odds Ratio & $\begin{array}{l}\mathrm{b} \\
\text { Linearized SE }\end{array}$ & $\mathrm{t}, \mathrm{p}>0$ & Tolerance \\
\hline Education Gap & $1.132 *$ & $\begin{array}{l}0.124 \\
0.039 \\
\end{array}$ & $3.10,0.002$ & 0.99 \\
\hline $\begin{array}{l}\text { Husband's } \\
\text { Age }\end{array}$ & 1.044 & $\begin{array}{l}0.043 \\
0.024\end{array}$ & $1.80,0.072$ & 0.47 \\
\hline Wife's Age & 0.922 & $\begin{array}{l}-0.081 \\
0.024\end{array}$ & $-3.27,0.001$ & 0.47 \\
\hline Constant & 0.270 & $\begin{array}{l}-1.310 \\
0.552\end{array}$ & $-2.37,0.018$ & \\
\hline \multicolumn{4}{|c|}{$*$ Values significant at 0.05 or above } & \\
\hline
\end{tabular}

Model 4 (Table 4-6) examined the same effect as in Model 3, but for black women. Status exchange theory did not expect any significant relationship for black women, and thus I did not hypothesize a significant effect (see above hypotheses). The regression results shown in Table 4-6 show that there is no statistically significant effect between the education gap and the odds of intermarriage for black women. 


\begin{tabular}{|c|c|c|c|c|}
\hline \multicolumn{5}{|c|}{$\begin{array}{l}\text { Table 4-6. Logistic Regression Results: Status Exchange The } \\
\text { Wives in Metropolitan Statistical Areas. } \\
\mathrm{N}=216,569 \text { (Weighted) }\end{array}$} \\
\hline Model 4 & Odds Ratio & $\begin{array}{l}\mathrm{b} \\
\text { Linearized SE }\end{array}$ & $\mathrm{t}, \mathrm{p}>0$ & Tolerance \\
\hline $\begin{array}{l}\text { Education } \\
\text { Gap }\end{array}$ & 0.939 & $\begin{array}{l}-0.063 \\
0.098\end{array}$ & $-0.64,0.523$ & 0.98 \\
\hline $\begin{array}{l}\text { Husband's } \\
\text { Age }\end{array}$ & 0.987 & $\begin{array}{l}-0.013 \\
0.030\end{array}$ & $-0.43,0.664$ & 0.45 \\
\hline Wife's Age & 0.985 & $\begin{array}{l}-0.020 \\
0.036\end{array}$ & $-0.55,0.582$ & 0.46 \\
\hline Constant & 0.118 & $\begin{array}{l}-1.972 \\
0.805\end{array}$ & $-2.45,0.014$ & \\
\hline \multicolumn{4}{|c|}{ *Values significant at 0.05 or above } & \\
\hline
\end{tabular}

\section{Summary}

This chapter examined both structural assimilation theory and status exchange theory for both black husbands and black wives to obtain a further understanding of intermarriage trends for both sexes. I do not intend to create a comprehensive model to explain the incidence of intermarriage but to understand which predictors had an effect on the incidence of intermarriage. I found that my hypotheses regarding structural assimilation theory were supported for both black husbands and black wives. Each model showed significant effects in the predicted direction. On the other hand, status exchange theory found support for black husbands but not for black wives. I take these findings into consideration in my next chapter where I will estimate multi-level logistic regression models. 


\section{CHAPTER V}

\section{MULTILEVEL ANALYSES OF INTERRACIAL MARRIAGES}

In this chapter, I estimate multilevel models of the log odds of black men being in interracial marriages. I use multilevel analysis to introduce explanatory variables from the metropolitan areas where the black men reside. Multilevel analysis allows the researcher to not only ascertain the degree to which individual-level characteristics impact the log odds of intermarriage but also how the characteristics of the metropolitan areas affect the log odds of intermarriage for black men. The context in which black men live should hopefully enhance our understanding of why they may or may not partake in interracial marriages beyond just examining the effects of their personal characteristics.

Three random effects models are estimated to investigate the likelihood of interracial marriage for black men. I do not evaluate comparison multilevel models for black women because of a lack of variance at the contextual level. Specifically, I will explore how the characteristics of the black men themselves, along with the contextual characteristics of their respective metropolitan areas, impacted their log odds of being interracially married. In the sections below, I first outline the hypotheses associated with each model, followed by the operationalization of the independent variables. I next provide a statistical description of the level-2 contextual variables, then discuss the results of the models. Lastly, I engage in an exploratory analysis with cross-level interactions to investigate if there are any effects of the level-2 variables on the slopes of the level-1 variables predicting the likelihood of intermarriage for black men. 


\section{Hypotheses and Operationalization}

In Chapter 4, both independent variables of education (Model 1) and the education gap (Model 3) were shown to have consistent and significant effects on the log odds of intermarriage for metropolitan black men. Given this finding, these predictors were used as the level-1 variables in the two-level hierarchical random effect models presented here. Group size, racial heterogeneity, and sex ratio are used here as level-2 predictors of interracial marriage. Given that there were issues of multicollinearity with group size and the sex ratio, these variables were used in separate equations. In the next paragraphs, I review specific combinations of individual and contextual level variables.

I first examined the relationship between group size of a metropolitan area and the odds of interracial marriage for black men. The hypothesis is that as the size of a minority group increases in an area, the odds of interracial marriage decrease. Group size was measured by the proportion of black men to all person ages 18-64 within each metropolitan area.

Hypothesis 5: The larger the proportion of a minority group in an area, the less likely black men are to be in racial intermarriages

Model 5 estimated the direct effects of the level-1 variables of education and the education gap, plus the level-2 variable, group size, on the odds of intermarriage for black men. As stated in chapter 4, education is measured by the level of education attainment of the husband while the educational gap is measured as the absolute value of the difference between a husband and his spouse's level of education. 
Next, I investigated the association between racial heterogeneity of a metropolitan area and the likelihood of interracial marriage for black men. While Blau's structural theory predicts a positive relationship between racial heterogeneity and intermarriage after controlling for income, subsequent research has reported different results. More recent studies found either a negative or insignificant effect of racial heterogeneity on racial intermarriage (Cready and Saenz 1997; Hwang, Saenz, and Aguirre 1994). Cready and Saenz suggest that "increased heterogeneity should suppress the probability of outgroup contacts for [minorities] and enhance it for the [majority]" (Cready and Saenz 1997:355). The reasoning behind this positions lies in the possibility that minorities marrying in-group when more of their racial group are in the same area. In essence, this works alongside the group size theory for minorities where as the group gets larger, the more likely they are to marry within the group.

Hypothesis 6: The higher the racial heterogeneity (M6 index) of a metropolitan area, the lower the odds of intermarriage for black men.

Model 6 estimates the direct effects of the level-1 variables of education and the education gap, plus the level-2 variable, racial heterogeneity, on the odds of intermarriage for black men. Racial heterogeneity was measured with the M6 index (Gibbs and Poston 1975) by using four racial/ethnic categories: non-Hispanic black, non-Hispanic white, Hispanics, and Asians in the ages 18-64 within a metropolitan area. It is calculated for each of the metropolitan areas as:

$$
N c\left[1-\frac{(|x-x|) / 2}{\Sigma x}\right]
$$


where $\mathrm{N}_{\mathrm{c}}$ is the number of racial/ethnic categories containing at least one person. Also, " $x$ " is the number of persons in a racial/ethnic category (Cready and Saenz 1997).

Higher scores of the M6 index indicate higher levels of heterogeneity within a metropolitan area.

Lastly, I examine the relationship between the sex ratio (the number of men per 100 women) and the odds of intermarriage for black men. I operationalized this variable as the number of black men per 100 black women in their respective metropolitan area. Previous research has consistently reported that lower sex ratios among blacks lead to higher odds of intermarriage for black men (Cready and Saenz 1997; Crowder and Tolnay 2000). Following the previous literature, I expect to see a negative relationship between the sex ratio and the odds of intermarriage.

Hypothesis 7: The higher the sex ratio for blacks, the lower the odds of intermarriage for black men.

Model 7 estimates the direct effects of the level-1 variables of education and the education gap, plus the level-2 variable, the sex ratio, on the odds of intermarriage for black men.

\section{Descriptive Statistics of Contextual Variables}

A brief discussion of the descriptive statistics will now be provided for the contextual-level variables for the black husband's models (see Table 5-1). The analysis only includes metropolitan areas with at least 20 sample cases (households). 
The sample for black husbands (Table 5-1) includes 27 metropolitan areas. The three contextual variables are group size, racial heterogeneity and the sex ratio of the metropolitan area. The mean proportion of black males among all groups across the metropolitan areas was 10 percent, which means that on average, black males constitute about 10 percent of the population. The mean racial heterogeneity score for black males across the metropolitan areas was 2.3 with a minimum of 1.78 in Indianapolis, IN and a maximum of 2.94 in New-York-Newark, NY/NJ. The mean of the sex ratio is 80.9 among the metropolitan areas. The minimum sex ratio is 74.76 in New Orleans, and the maximum sex ratio is 87.66 in Jackson, MS.

\begin{tabular}{|c|c|c|c|c|}
\hline $\begin{array}{l}\text { Independent } \\
\text { Variable }\end{array}$ & Mean & $\begin{array}{c}\text { Standard } \\
\text { Deviation }\end{array}$ & Minimum & Maximum \\
\hline Group Size & 0.10 & 0.039 & 0.03 & 0.22 \\
\hline M6 & 2.32 & 0.35 & 1.78 & 2.94 \\
\hline Sex Ratio & 80.9 & 3.02 & 74.76 & 87.66 \\
\hline
\end{tabular}

\section{Multilevel Results}

\section{One-Way ANOVA Models}

Before I estimated my hierarchical models, I first estimated a one-way ANOVA model to ensure that a multilevel model was necessary for analysis. This one-way ANOVA model is fully conditional give that no independent variables are specified at any level. The one-way ANOVA provided a point estimate and confidence interval for 
the grand mean, $\gamma_{00}$ (Raudenbush and Bryk 2002:24). Moreover, it contains information about the outcome of the variability at each of the two levels" (Raudenbush and Bryk 2002:24). Essentially, a one-way ANOVA model allows one to understand how much variation in the dependent variable occurs between groups and how much occurs within groups by providing the intraclass correlation.

The ratio of level-2 variance to the total variation, or the intra-class correlation, is a useful index for the standard two-tiered hierarchical linear models. While this is a helpful measure, Raudenbush and Bryk (2002:298) warn "this measure is less informative in the case of nonlinear link function given the level-1 variance is heteroscedastic." To address this issue, Raudenbush and Bryk (2002:334) cite Snijner and Bosker (1999) suggestion of understanding the level-1 variance as a latent variable for an alternative estimation of intra-class correlation.

This new conceptualization of the intra-class correlation can be calculated as $\rho=$ $\tau_{00} /\left(\tau_{00}+\pi^{2} / 3\right)$, where $\tau_{00}$ is the level- 2 variance component and $\pi^{2} / 3$ is the level-1 component and is a constant.

Table 5-2 displays the one-way ANOVA models for black husbands and Table 53 for wives. The ANOVA model for the husbands indicates that most of the variation of interracial marriage took place at the individual level (within metropolitan areas).

However, there is a statistically significant amount of variation in the dependent variable between the metropolitan areas (i.e. level-2) for black husbands. Specifically, 5.4 percent of the variance in intermarriage occurs between metropolitan areas, and 94.6percent of the variation of racial intermarriage occurs at the individual level (i.e. within 
metropolitan area) for black husbands. In contrast, Table 9 shows that the in the oneway ANOVA model for black wives, there is not a statistically significant amount of variation at level-2. Hence I do not estimate multilevel models for the black wives.

\begin{tabular}{|l|l|}
\hline \multicolumn{2}{|l|}{ Table 5-2. One-way ANOVA Model, Black Husbands. } \\
\hline P-Value & $\tau_{00} /\left(\tau_{00}+\pi^{2} / 3\right)$ \\
\hline 0.000 & $5.4 \%$ \\
\hline
\end{tabular}

\begin{tabular}{|l|l|}
\hline \multicolumn{2}{|l|}{ Table 5-3. One-way ANOVA Model, Black Wives. } \\
\hline P-Value & $\tau_{00} /\left(\tau_{00}+\pi^{2} / 3\right)$ \\
\hline 0.381 & $1.0 \%$ \\
\hline
\end{tabular}

\section{Multilevel Models}

Tables 5-4 through 5-7 display the results of the random effects analyses for black husbands. In the upcoming paragraphs, I will provide interpretations of each of the $\gamma_{\mathrm{xx}}$ (gamma) coefficients from these models. I have converted the logistic regression coefficients into odds ratios. To reiterate, my analyses here only address the direct effects of the level-1 and level-2 variables on the likelihood of intermarriage.

Model 5 (Table 5-4) examines the effect of both level-1 variables, educational attainment and the educational gap, and one level-2 variable, the proportion of black males in the ages 18-64 in a metropolitan area, on the odds of interracial marriage for black men. Model 5 shows a positive effect for only the educational attainment variable but no statistically significant effect for the educational gap variable. Now for the level-2 variable, group size, we see a negative effect that is statistically significant. Hypothesis 5 
was supported and confirms previous research that has shown that there is a negative relationship between minority group size and the odds of intermarriage (Cready and Saenz 1997).

\begin{tabular}{|l|l|l|l|}
\hline \multicolumn{3}{|l|}{ Table 5-4. Odds Ratios and Coefficients for Individual and Group Size } \\
Characteristics on the Likelihood of Being Intermarried for Black Men. \\
\hline Random Effect & Odds Ratio & $\begin{array}{l}\text { Coefficient } \\
\text { SE }\end{array}$ & T, p $>0$ \\
& & $\begin{array}{l}-3.207 \\
1.114\end{array}$ & \\
\hline \multicolumn{1}{|l|}{ Intercept } & -3.207 & -12.064 & $-6.92,0.00$ \\
\hline \multicolumn{1}{|c|}{$\begin{array}{l}\text { Proportion of } \\
\text { Black men in a }\end{array}$} & 5.76 e-06* & 1.744 & \\
MSA & & 0.065 & $1.95,0.051$ \\
\hline $\begin{array}{l}\text { Educational } \\
\text { attainment }\end{array}$ & $1.07^{*}$ & 0.034 & $1.40,0.162$ \\
\hline Education Gap & 1.060 & 0.058 & \\
\hline
\end{tabular}

Model 6 (Table 5-5) investigates the effects of the two level-1 variables, educational attainment and educational gap, and one level-2 variable, racial heterogeneity (M6 Index) on the odds of intermarriage of black men. Model 6 shows only a positive effect for educational attainment but no significant effects for either the educational gap variable or the level-2 variable of group size. Hypothesis 6 was not supported. This finding is surprising given that previous literature predicts a negative effect of heterogeneity on intermarriage for black men. 


\begin{tabular}{|c|c|c|c|}
\hline \multicolumn{4}{|c|}{$\begin{array}{l}\text { Table 5-5. Odds Ratios and Coefficients for Individual and Racial } \\
\text { Heterogeneity Characteristics on the Likelihood of Being Intermarried for } \\
\text { Black Men. }\end{array}$} \\
\hline Random Effect & Odds Ratio & $\begin{array}{l}\text { Coefficient } \\
\text { SE }\end{array}$ & $\mathrm{T}, \mathrm{p}>0$ \\
\hline Intercept & 1.705 & $\begin{array}{l}-1.705 \\
0.464\end{array}$ & \\
\hline M6 Index & 0.926 & $\begin{array}{l}-0.076 \\
0.332\end{array}$ & $-0.23,0.818$ \\
\hline $\begin{array}{l}\text { Educational } \\
\text { attainment }\end{array}$ & $1.06^{*}$ & $\begin{array}{l}0.067 \\
0.034\end{array}$ & $1.97,0.049$ \\
\hline Education Gap & 1.060 & $\begin{array}{l}0.058 \\
0.040\end{array}$ & $1.45,0.146$ \\
\hline
\end{tabular}

Model 7 (Table 5-6) shows the effects of the level-1 variables, educational attainment and educational gap, and one level-2 variable, the black sex ratio, on the odds of intermarriage for black men. Model 7 shows only a positive effect for educational attainment but no effects for the level-1 variable, education gap, or the level-2 variable, sex ratio. Hypothesis 7 was not supported. Previous research has shown that the sex ratio has a negative effect on the odds of intermarriage for black men: the lower the ratio of black men to women in a metropolitan, the higher the odds of intermarriage. My analyses did not provide support for this hypothesis. 


\begin{tabular}{|l|l|l|l|}
\hline $\begin{array}{l}\text { Table 5-6. Odds Ratios and Coefficients for Individual and Black Sex Ratio } \\
\text { Characteristics on the Likelihood of Being Intermarried for Black Men. }\end{array}$ \\
\hline Random Effect & Odds Ratio & $\begin{array}{l}\text { Coefficient } \\
\text { SE }\end{array}$ & T, p $>0$ \\
\hline Intercept & 1.710 & -1.710 & \\
& & 0.457 & \\
\hline Sex Ratio & 0.969 & -0.032 & $-0.23,0.818$ \\
& & 0.050 & $1.97,0.049$ \\
\hline Educational & $1.07^{*}$ & 0.067 & $1.45,0.146$ \\
attainment & & 0.034 & \\
\hline Education Gap & 1.060 & 0.058 & 0.040 \\
\end{tabular}

\section{Cross-Level Interactions}

In addition to understanding the direct effects of the level-2 variables on the odds of intermarriage for black men, I was also interested in the cross-level interactions (CLIs) of the level-2 variables on the slopes of the level-1 variables on the odds of interracial marriage. Specifically, I wished to examine how the level-2 variables affect the slopes of the level-1 education variable on the odds of intermarriage. I only examine the CLIs on the educational attainment slopes, and not on the education gap slopes because the effect of the latter education variable on intermarriage was not shown to be significant in any of the previously estimate multilevel models.

I thus have 3 additional hypotheses that specifically address this interest: group size, racial heterogeneity, and sex ratio separately influencing the slope of education and the odds of intermarriage. Tables 5-7 through 5-9 display the results of these cross-level interactions on the outcome of intermarriage for black men. Given that I have not come across literature that directly tests any of these interactions, I have assumed the 
associations of the direct effects of level-2 variables on the odds of intermarriages will be similar to those on the slope of education.

The first cross-level interaction I investigated was the interaction of proportion of black males and level of education.

Hypothesis 8: As the group size increases, the slope of educational attainment on the odds of intermarriage will decrease

My reasoning here is that as the proportion of blacks in an MSA increases, education may not matter as much as more blacks in an MSA could lead to more same race marriage between higher status blacks which would decrease the odds of intermarriage.

Next, I examined the cross-level interaction between racial heterogeneity and level of education.

Hypothesis 9: As racial heterogeneity increases, the slope of educational attainment on the odds of intermarriage will decrease.

The logic behind this hypothesis is that as an MSA becomes more racial diversity, the level of education of blacks who intermarry would be deemphasized.

Lastly, I explored the cross-level interaction between the sex ratio and level of education.

Hypothesis 10: As the sex ratio increases, the slope of educational attainment on the odds of intermarriage will decrease.

I believe this would be the case because as black men would increasingly outnumber black women, these black men of all socioeconomic backgrounds would marry black 
women and thus those who marry out would not have to be as concerned about education in respect to outmarriage.

\section{Cross-Level Interaction Results}

Model 8 (Table 5-7) investigates the cross-level interaction of group size on the slope of educational attainment and intermarriage. The odd ratios for the effect of group size on the slope of education and intermarriage are not statistically significant. This finding does not confirm hypothesis 8 .

\begin{tabular}{|c|c|c|c|}
\hline Random Effect & Odds Ratio & $\begin{array}{l}\text { Coefficient } \\
\text { SE }\end{array}$ & $\mathrm{T}, \mathrm{p}>0$ \\
\hline Intercept & 3.117 & $\begin{array}{l}3.117 \\
0.806\end{array}$ & \\
\hline $\begin{array}{l}\text { Proportion of } \\
\text { Black men in a } \\
\text { MSA }\end{array}$ & 45.775 & $\begin{array}{l}3.824 \\
12.972\end{array}$ & $0.29,0.768$ \\
\hline $\begin{array}{l}\text { Educational } \\
\text { attainment }\end{array}$ & 1.191 & $\begin{array}{l}0.175 \\
0.104\end{array}$ & $1.69,0.092$ \\
\hline $\begin{array}{l}\text { Proportion Black x } \\
\text { Education }\end{array}$ & 0.305 & $\begin{array}{l}-1.187 \\
0.951\end{array}$ & $-1.25,0.212$ \\
\hline Education Gap & 1.060 & $\begin{array}{l}0.059 \\
0.040\end{array}$ & 1.480 .139 \\
\hline
\end{tabular}

Model 9 (Table 5-8) examines the cross-level interaction between the M6 index and the slope of education on intermarriage. This CLI also is not significant. This finding does not confirm hypothesis 9 . 


\begin{tabular}{|c|c|c|c|}
\hline Random Effect & Odds Ratio & $\begin{array}{l}\text { Coefficient } \\
\text { SE }\end{array}$ & $\mathrm{T}, \mathrm{p}>0$ \\
\hline Intercept & 1.701 & $\begin{array}{l}-1.70 \\
0.468\end{array}$ & \\
\hline M6 Index & 1.58 & $\begin{array}{l}0.459 \\
1.293\end{array}$ & $0.35,0.723$ \\
\hline $\begin{array}{l}\text { Educational } \\
\text { attainment }\end{array}$ & 1.181 & $\begin{array}{l}0.166 \\
0.240\end{array}$ & $0.69,0.488$ \\
\hline M6 x Education & 0.961 & $\begin{array}{l}-0.040 \\
0.097\end{array}$ & $-0.41,0.681$ \\
\hline Education Gap & 1.060 & $\begin{array}{l}0.057 \\
0.040\end{array}$ & $1.44,0.151$ \\
\hline
\end{tabular}

Model 10 (Table 5-9) shows the cross-level interaction between the sex ratio and the slope of educational attainment and intermarriage. As with the above CLIs, this CLI also is not statistically significant. This finding does not confirm hypothesis 10 . 


\begin{tabular}{|c|c|c|c|}
\hline Random Effect & Odds Ratio & $\begin{array}{l}\text { Coefficient } \\
\text { SE }\end{array}$ & $\mathrm{T}, \mathrm{p}>0$ \\
\hline Intercept & 1.713 & $\begin{array}{l}-1.713 \\
0.471\end{array}$ & \\
\hline Sex Ratio & 0.819 & $\begin{array}{l}-0.199 \\
0.125\end{array}$ & $-1.60,0.110$ \\
\hline $\begin{array}{l}\text { Educational } \\
\text { attainment }\end{array}$ & 0.394 & $\begin{array}{l}-0.932 \\
0.865\end{array}$ & $-1.08,0.282$ \\
\hline $\begin{array}{l}\text { Sex Ratio x } \\
\text { Education }\end{array}$ & 1.01 & $\begin{array}{l}0.012 \\
0.011\end{array}$ & $1.16,0.245$ \\
\hline Education Gap & 1.06 & $\begin{array}{l}0.058 \\
0.040\end{array}$ & $1.45,0.146$ \\
\hline
\end{tabular}

\section{Summary}

This chapter utilized random-effect multilevel modeling to perform analyses of the probability of interracial marriage for metropolitan black men. My primary objective was to assess how the individual-level characteristics of black men, as well as the contextual-level characteristics of their metropolitan areas, impacted the odds of being intermarried. To my surprise, only Model 5 out of the three models without interaction variables showed any significant effects of metro context on interracial marriage for black men. Only hypothesis 5 was supported.

In addition to the direct testing of each level-2 variable on the odds of intermarriage for black men, I also was interested in the cross interaction between the metropolitan contexts and the slopes of educational attainment on intermarriage. I found that none of the CLIs were statistically significant. 
My suspicion as to why so few of the level-2 variables had any statistical significance lies in the lack of variance in intermarriage among the metropolitan areas. My sample was severely impacted by the requirement that I restrict the analysis to currently married men who married within the past twelve months. While previous literature did not have an exact way of knowing when couples were married, they were free to estimate a time in which a marriage was contacted. This allowed them to have more couples who may or may not be the most recently married. 


\section{CHAPTER VI}

\section{CONCLUSIONS AND FUTURE RESEARCH}

This goal of this dissertation was to address the effects of education and spatial context on the likelihood black intermarriage. Specifically, an emphasis was placed on whether or not residential context affects black men and women differently. To assess the impacts of both educational and contextual impact on interracial marriage trends, I had three objectives. The first was to evaluate statistically two micro-level theoretical frameworks of black interracial marriage. The second was to implement multilevel modeling to explore how individual and contextual level characteristics affect the probability of being interracially married. Exploratory in nature, the third objective assessed the impact of cross-level interactions on the slopes of education in predicting intermarriage.

The primary findings of this dissertation are that education and context both impact the odds of intermarriage of black men. Specifically, the level-1 variables of educational attainment and the education gap were positively related with the odds of intermarriage. When context was considered, only group size was found to be statistically significant. As for black women, similar results were found with the level-1 variables, but data issues did not allow for an analysis of the contextual effects on the likelihood of intermarriage for black women. I will address this matter later.

The significance of these findings to the field of sociology is related to the implementation of hierarchical linear modeling to test status exchange models. Status 
exchange theory was used here to evaluate gender differences in outmarriage rates among blacks only using individual characteristics and contextual characteristics. Most studies using status exchange theory considering context have used introduced explanatory variables at two levels. But most of these analyses have been undertaken without incorporating true multilevel models.

While multilevel modeling is not new to status exchange work, contextual characteristics are usually disaggregated down to the level of the individual, which leaves out the importance of context. This dissertation differs in that I use a statistically appropriate technique to model the effects of education and context on the odds of black intermarriage. This distinction is important because as Merton himself notes, context has an impact on in and out-marriage rates (see Merton 1941:220-221). My research is an improvement on earlier work because I am using the data of the context to predict intermarriage independent of the data of the individual level. Hierarchical linear modeling adds more confidence in understanding how variation at the contextual level impacts the probability of intermarriage compared to models that disaggregate context down to the individual level.

While I was able to accomplish each objective predicting whether or not black men intermarried, I could not do the same for black women. In this concluding chapter, I summarize my research and findings, address limitations, and offer future direction in the demographic and sociological study of interracial marriage. 


\section{Level One Analyses}

My first level of analyses, presented in Chapter 4, tested the effectiveness of two well-known micro-level theories of interracial marriage: structural assimilation theory and status exchange theory. Structural assimilation theory predicts a positive relationship between education/SES and interracial marriage. The premise for this theory prediction lies in the assumption that the U.S. emphasizes democratic and universalistic norms within its education system; increases in levels of educational attainment should thus increase the likelihood of interracial marriage (Gullickson 2006; Lieberson and Waters 1988). Merton's Status exchange theory's central argument is that marriages between blacks and whites are an exchange of high SES/prestige of the black spouse for the high social class status of the white spouse. Merton was interested in the differential blackwhite marriage rates where there was an apparent gap between the rates of outmarriage for black men compared to black women. While his analysis was primarily theoretical, the empirical testing of status exchange models of interracial marriage has shown mixed results; this is especially the case with respect to whether the effect of status exchange persists regardless of the gender of the black spouse.

Researchers investigating status exchange theory have employed various types of data and have used an assortment of statistical techniques (Kalmijn 1991; Kalmjin 1993; Cready and Saenz 1997; Hou and Myles 2013; Gullickson and Torche 2014). Many investigators have used log-linear models of education to predict intermarriage; these models have been used primarily because of the nature of the categories used in the analysis (Qian 1997; Fu 2001; Rosenfeld 2005). This dissertation differs in that I employ 
logistic regression models that include interval measures of educational attainment. This is an advantage over the log-linear models is my use of a predictor variable based on interval data. Also, many of the earlier works used census data from the 1980 or 1990 decennial censuses; in my analyses I used data from the 2008-2014 American Community Surveys. The primary advantage of using ACS data over decennial census data is that I have access to much more current data that are better able to reflect current trends.

In my level-1 analyses, I estimated four logistic regression equations to evaluate two theories of intermarriage. My goal was to ascertain which variables influenced the likelihood of being intermarried, which variable was the most important, and whether it varied by gender.

In the first two models, I explored the probabilities of intermarriage between 2008-2014 for over 250 thousand black men and over 216 thousand black women; both the men and women were living in U.S. metropolitan areas. I assessed the degree to which a structural assimilation theory variable, the level of education of the black spouse, was associated with the likelihood of being interracially married. Structural assimilation theory expects that as education levels increase, so do the odds of interracial marriage. Thus I hypothesized a positive relationship between educational attainment and the log odds of intermarriage for both black men and black women.

The results from both Model 1 and Model 2 confirmed the structural theory argument. In each model educational attainment had a positive and significant effect on the log odds of intermarriage. Model 1 showed that for each one-year increase in the 
level of education, the odds of intermarriage increased by 13 percent, other things being equal. Model 2 had similar findings in that for each one-year increase in the level of education, there was a 14 percent increase in their odds of intermarriage, other things being equal. The assumptions of structural assimilation for both black men and women were upheld.

In Model 3 and Model 4 I introduced the key X variable of the education gap and examined its impact on the odds of racial intermarriage for the same groups of black men and black women living in the metropolitan areas of U.S. The assumption of status exchange theory is that black males exchange high SES/prestige for the social class of their white female spouse. For black males, I predicted as the education gap between his level of education and her level increased, the odds of intermarriage would increase. For black females, there was no predicted relationship.

The results from Model 3 supported status exchange theory. The effect of the education gap was positive and statistically significant. For each one-year increase in the education gap between the black male and his female spouse, the odds of intermarriage increase by 13 percent, all else equal. Model 4, as mentioned before, did not have a prediction, and results did not show a statistically significant effect on education gap and the odds of intermarriage for black women. These findings stand with most recent literature that suggests status exchange is partially supported when it comes to black men but not supported when in regards to black women.

In closing, structural assimilation theory was supported by my analyses for both black men and women; status exchange theory was accorded support from my analyses 
but only for black men. Both theories seek to understand the role of education in the predicting the odds of blacks intermarrying. Structural assimilation focuses on the level of education of the black spouse to predict intermarriage chances while status exchange theory looks at the distance in educational level between the husband and wife as a predictor of intermarriage. The former shows that for both black men and women, as their levels of education increase, so does their odds of intermarriage. The latter illustrates that education.

Even with completing my analysis, there were some issues with my individual analyses that I will now address. The problem of simultaneity bias which is a statistical issue whereby the characteristics of individual variables were measured after the occurrence of the dependent variable. Specifically, I would want to know the level of education of person before they got married if I am using education as a predictor of intermarriage. Education, like age or SES, changes over time so we cannot assume that education level noted at the time the ACS form was completed is the level education the person had when they got married. Given that the ACS does not ask for education before marriage, one way to work around this issue is to restrict the analysis to individuals who were married within the past twelve months of when the ACS was conducted. Chances are most individuals who are recently married are not moving regarding educational attainment at that time. The downside to this approach is that it limits the number of intermarried couples available for analysis even with combining datasets. Overall, I am satisfied. I was able to work around the simultaneity bias issue. 
Regarding methodology, I was content with my selection of logistic regression as it allowed me to incorporate interval variables in my model. If I were to use log-linear modeling, I would not have been able to use as many education categories and thus possible confound my findings as it would not allow as much variation with reduced categories. Log-linear has been the mainstay of much intermarriage work (Kalmijn 1991; 1993; Qian 1997, Fu 2001; Rosenfeld 2005), logistic regression, as a more complex modeling approach, has become more prominent in the field recently (Hou Myles 2013; Gullickson and Torche 2014). My conclusions would be more convincing in regards to my two theories if they had they been subjected to various types of statistical tests.

\section{Multilevel Analyses}

In Chapter 5, I used hierarchical generalized linear models (HGLMs) to do multilevel analyses of the log odds of metropolitan black men being in interracial marriages. This approach allowed me to investigate the extent to which the characteristics of the men themselves, alongside the context characteristics of their metropolitan areas, affected the odds of intermarriage. I will review my hypotheses, discuss my results and address issues of the analyses.

The education attainment and education gap variables that were used as the level one in the multilevel HGLM model since each had effects on the probability of intermarriage for both black men and women. I incorporated several predictors: group 
size, M6 index, and sex ratio at the contextual level and the slopes of each were treated as random.

In Model 5, I examined intermarriage probabilities in 2008-2014 of 1,675 black men living in 26 metropolitan areas of the United States. Model 5 reviewed the extent to which both level-1 variables, education attainment and education gap, and one level-2 variable, the group size of black men, were associated with the likelihood for black men to be interracially married. Structural assimilation theory suggests a positive relationship between the level of education and intermarriage. Thus I hypothesize as husband's education increases, so does his odds of intermarriage. Status exchange predicts a positive relationship between the distance in education between a husband and his spouse. Thus I hypothesize that has the distance in the level of education increases between a husband and wife, so does the odds of intermarriage. In keeping with group size theory that states that as group size increases, the odds of intermarriage decrease, thus I predict a negative relationship between group size and the odds of intermarriage.

At the individual level, I found that only education attainment was positive and statistically significant in the probability of intermarriage for black men. At the contextual level, I found a negative and statistically significant relationship between group size and likelihood of intermarriage that confirms previous research. The larger the proportion of black men within a metropolitan area, the less likely they are to be interracially married.

Model 6 looks at how level-1 variables, education attainment and education gap and one level-2 variable, M6 index (racial heterogeneity), were related to the likelihood 
of black men being intermarried. As explained before, both education attainment and education were predicted to be positively related to the odds of intermarried. Racial heterogeneity suggests that as an area becomes more racially diverse, the odds of intermarriage will decrease. I predicted a negative relationship between racial heterogeneity and intermarriage.

At the individual level, I only found a positive and statistically significant relationship between education attainment and intermarriage. There was no significant effect for education gap on the odds of intermarriage. At the contextual level, there was no significant effect of racial heterogeneity on the odds of intermarriage. This did not confirm previous literature that predicted a negative impact of racial heterogeneity on intermarriage.

Model 7, examines to which extent both level-1 variables, educational attainment and education gap, and one level-2 variable, the sex ratio of the black population, influences the probability of intermarriage of black men in metropolitan areas. For reasons discussed above, level-1 variables educational attainment and education gap are expected to have positive relationships with the odds of intermarriage. Previous research indicates when the black sex ratio of a metropolitan is small that there is a greater chance they will be in an interracial marriage. Thus, I hypothesize a negative relationship between sex ratio and the log odds of intermarriage for metropolitan black men.

At the individual level, I found that only education attainment had a positive and significant effect on the probability of intermarriage for black men. There was no significant effect for education gap on the log odds of intermarriage for black men. At 
the contextual level, there were no effects for sex ratio. This finding did not uphold previous literature that predicts a negative relationship between sex ratio and odds of being intermarried for black men.

My multilevel analyses also included an exploratory analysis of the cross-level interactions (CLI) where the primary goal was to examine the impact level-2 variables had on the slope of the educational attainment slopes. The education gap variable proved to have no effect in previous estimated multilevel models thus it was excluded from the analysis here. Given that to my knowledge, no research has looked at CLI using multilevel modeling, my hypotheses are primarily based on my understanding of the relationships exhibited above. For instance, if there were a negative relationship between the level-2 variable and the odds of intermarriage, I would predict a similar relationship with the effect on the slope of education in a cross-level interaction.

In Model 8, I examined the CLI between level-1 variable, education attainment, and level-2 variable, group size, of a multilevel model, which included 1,675 black men from 2008-2014 living in 27 metropolitan areas. I estimated the extent to which the slope of education was affected by the black male group size of the metropolitan area. I found no significant effect of the CLI on the slope of education.

In Model 9, I investigated the CLI between the slope of level-1 variable, education attainment, and level-2 variable, M6 index on the odds of intermarriage. I found no effect of the CLI. 
In Model 10, I investigated the CLI between the slope of level-1 variable, education attainment, and level-2 variable, sex ratio on the odds of intermarriage. I found no effect of the CLI.

In closing, my multilevel analyses showed that context matters in some regard in predicting interracial marriage among metropolitan black men and women in the U.S. I found both individual-level variables of black men and women and contextual-level variables of their metropolitan areas, were shown to have an impact on the probability of intermarriage. Any future research would benefit from including the social context when examining interracial marriage, specifically with employing multilevel modeling using hierarchal linear modeling. This particular approach has not been highly utilized in this area of research.

My testing of both structural assimilation and status exchange theory would have been enhanced from a larger dataset but restricting my sample to only newly married couples prevented a larger sample. As for my multilevel models, having a larger sample would have been more beneficial for my analyses. Given the limited sample size, there issues with my analyses regarding the inability to examine the relationship of context and outmarriage for black women and lack of substantial variation in two of three contextual variables for black men.

An issue I encounter was that I was not able to conduct multilevel analyses for black women in metropolitan areas due to lack of variation at level-2. In an ideal world, this particular analysis of contextual effects and the odds of intermarriage of black women is necessary to further understand the gender differentials in intermarriage rates 
between black men and women. This gender comparison would help with consistency with my investigation with level-1 variables in Chapter 4.

While the variation of black men at level-2 was statistically significant, it was not large. This statistical fact I believe played a great role in the lack of significance of the effect of some of the level-2 variables on the odds of intermarriage. For instance, previous research showed M6 index as a variable that impacts the odds of intermarriage, but I found no effect. I only used four racial categories while previous studies used more racial categories to reflect racial diversity. The use of more racial categories would assume more variation to take place at level-2 thus a greater chance of seeing an impact on the odds of intermarriage for black men.

When it comes back to my initial question of whether context matters; I have two answers: yes and no. My research shows that context matters for black men but not for black women. I believe the statistical shortcomings noted above justify my stance. I will say that maybe context matters less for women than men when to comes to the sex ratio variable.

While I had a larger dataset, the restrictions to only include first marriages and marriages within the previous 12 months impacted my sample for both intermarried black men and women. Given that intermarriages are more likely to occur after first marriages, there may have been more variation for to counteract the issues mentioned above. 


\section{Discussion and Future Research}

If I were to conduct this same research again using ACS data, I would continue to merge several single year datasets as they allow the researcher to have a larger sample. While interracial marriage rates are on the rise in the U.S., they are still relatively low and thus reflected in ACS samples I used. These small numbers in my sample created statistical issues at several points in the dissertation. These issues were explained in Chapter 5 as the data restrictions reduced my sample to where conducting an analysis of black women at the contextual level was not possible. The primary reason for this unfeasible task was the lack variation at level-2 for black women compared to black men.

I believe a qualitative component to my dissertation would also improve the quality of my work. Conducting 30-40 interviews with both individual and married black men and women to understand how they view education and where they live as predictors of how they find/found as potential spouses. Qualitative work would help me understand how people rationalize their actions, in this event, intermarriage. Mixed methods are a preferred approach as it allows one to help triangulate data and provide a more in-depth narrative about intermarriage. I also would like to hold focus groups that will allow for more variation that may not be present at individual interviews.

My future research would extend my dissertation in several ways. I would be interested in seeing how the education gap compares between blacks that intermarry with whites vs. those who intermarry with other racial/ethnic groups. My prediction is that the non-black racial/ethnic minorities' education gap with their spouses would be 
less than the black-white couples given the racial history of the U.S. Also, comparing the contextual effects of intermarriage of blacks, Latinos, and Asians with whites. Past research has found effects of context on the odds of intermarriage for Asians (Hwang, Saenz, and Aguirre 1994; Hwang, Saenz, and Aguirre 1997), for Latinos (Cready and Saenz 1997), and blacks (Mitchell-Kernan 1990; Crowder and Tolnay 2000; Hou and Myles 2013; Gullickson 2014). This dissertation uses hierarchical linear modeling which none of the above research uses to examine direct effects of level-2 variables on levelone variables to avoid the issue of disaggregation of data. In conducting such a statistical approach across each of these racial/ethnic groups would allow a researcher to see how contextual effects differentially impact each group. I believe this knowledge would vastly improve our understanding of intermarriage patterns.

Another way to expand my research is to look at how status exchange theory would predict the odds of intermarriage for same-sex individuals. Rosenfeld (2007) asserts that interracial couples and same-sex couples are similar in that many in our society still see these pairings as a social taboo. Given this logic, I would inquire if the way that status exchange uses race as currency in a different-sex marriage, does it play out the same in same-sex marriages. The immediate issue I note is that we cannot account for sex difference given hat same-sex couples do not vary with sex. To account for this, one could do interviews with same-sex interracial couples to understand what each person values about the other and gauge if there were "exchanges" in other areas. To do this quantitatively would be a challenge but it can be done. Gary Gates (2015) has developed a sophisticated process of how to create a dataset of same-sex couples using 
ACS data before 2013. As of 2013, ACS included a same-sex married variable that allows users to analyze data concerning same-sex married individuals. This variable only covers from 2013 and 2014 at the moment.

The incorporation of both different interracial combinations, both same-sex and different sex would help develop a comprehensive theoretical framework about how interracial marriages operate in the United States. I believe this is the direction that both demographers and sociologists are heading as our society continues to accept what were formally illegal practices in the U.S. As of 2015, the United States Supreme Court struck down the ban on same-sex marriage in the case of Obergefell vs Hodges which will lead to more scholars to engage in how different marriage markets work based on whether individuals prefer different sex or same sex partners. It will be interesting to see how gender works for both couple types as we continue to accrue more census data on same sex couples. 


\section{REFERENCES}

American Community Survey (ACS). 2006. United States Census Bureau. Washington, D.C.

. 2003. "American Community Survey Operations Plan," United States Census

Bureau. Washington, D.C.: Government Printing Office.

Anderson, Robert and Rogelio Saenz. 1994. "Structural Determinants of Mexican

American Intermarriage, 1975-1980.” Social Science Quarterly 75 (2):414-430.

Anderton, D. L. and D. E. Sellers. 1989. "A Brief Review of Contextual-Effect Models and Measurement," Historical Methods 22(3) (Summer):106-15.

Baumle, Amanda K. and Dudley L. Poston, Jr. 2011. "Economic Cost of

Homosexuality: Multilevel Analyses,” Social Forces 89(3):1005-1032.

Blau, Peter M. 1977. “A Macrosociological Theory of Social Structure.” The American Journal of Sociology 83(1):26-54.

Blau, Peter M., Terry C. Blum, and Joseph Schwartz. 1982. "Heterogeneity and Intermarriage." American Sociological Review 47(1):45-62.

Blau, Peter M. and Joseph E. Schwartz. 1984. Crosscutting Social Circles: Testing a Macrostructural Theory of Intergroup Relations. Orlando: Academic Press.

Blum, Terry. 1985. "Structural Constraints on Interpersonal Relations: A Test of Blau's Macrosociological Theory." The American Journal of Sociology 91(3):511-521.

Campbell, Mary E. and Molly Martin. 2015. "Race, Immigration and Exogamy among the Native Born: Variation across Communities." Sociology of Race and Ethnicity. 2(2):142-161.

Cready, Cynthia M., and Rogelio Saenz 1997 'The Nonmetro/metro context of racial/ethnic outmarriage: Some differences between African Americans and Mexican Americans." Rural Sociology 62(3):335-362.

Crowder, Kyle and Stewart Tolnay. 2000. A New Marriage Squeeze for Black Women: The Role of Racial Intermarriage by Black Men. Journal of Marriage and Family 62(3):792-807.

DiPrete, T. A. and J. D. Forristal. 1994. "Multilevel Models: Methods and Substance," Annual Review of Sociology 20(1): 331-357. 
Drake, St. Clair and Horace Cayton. 1945. Black Metropolis: A Study of Negro Life in a Northern City, rev. ed. Chicago: University of Chicago Press.

de Leeuw, Jan. 2002. "Introduction." Pp. xix-xxii. Hierarchical Linear Models:

Applications and Data Analysis Methods, Second Edition. Stephen W. Raudenbush and Anthony S. Bryk, editors. New York: Sage Publications.

DuBois, W.E.B 1899. The Philadelphia Negro: A Social Study. New York: Shocken.

Fossett, Mark and Jillian Kiecolt. 1993. "Mate Availability and Family Structure among African Americans in U.S. Metropolitan Areas." Journal of Marriage and Family, 55(2): 288-302.

Fu, Vincent Kang. 2001. "Racial Intermarriage Pairings.” Demography 38(2)147-59.

Gates, Gary J. 2015. Demographics of Married and Unmarried Same-Sex Couples:

Analyses of the 2013 American Community Survey. Los Angeles, CA: UCLA School of Law.

Gibbs, Jack P and Dudley L Poston, Jr. 1975. “The Division of Labor: Conceptualization and Related Measures." Social Forces 53(3):468-76.

Gordon, Milton. 1964. Assimilation in American Life: The Role of Race, Religion and National Origins. New York: Oxford University Press.

Greenwood, Michael J. 1975. "Simultaneity bias in migration models: An empirican examination." Demography 12(3):519-536.

Gullickson, Aaron. 2006. "Education and Black-White Intermarriage." Demography 43(4):673-689.

Gullickson, A \& Torche, Florencia. (2014). "Patterns of Racial and Educational Assortative Mating in Brazil.” Demography 53(3): 835-856.

Heer, D. 1974. "The Prevalence of Black-White Marriage in the United States, 1960 and 1970." Journal of Marriage and the Family 36(2):246-58.

Hwang, Sean-Shong, Rogelio Saenz, and Benigno E. Aguirre. 1994. "Structural and Individual Determinants of Outmarriage among Chinese-, Filipino-, and JapaneseAmericans in California." Sociological Inquiry 64(4):396-414. . 1997. "Structural and Assimilationist Explanations of Asian American Intermarriage." Journal of Marriage and Family 59 (3): 758-772. 
Jacobs, Jerry and Teresa G. Labov. 2002. "Gender Differentials in Intermarriage Among Sixteen Racial and Ethnic groups." Sociological Forum 17(4):621-646.

Kalmijn, Matthijs. 1993. "Trends in Black/White Intermarriage.” Social Forces 72(1):119-46. . 1998. "Intermarriage and Homogamy: Causes, Patterns, Trends." Annual Review of Sociology 24(1):395-421.

Lewis-Beck, Michael S. 1995. Data Analysis: An Introduction. Thousand Oaks, CA: Sage Publications.

Lee, Sharon M. and Edmonston. Barry. 2005. "New Marriages and New Families: U.S. Racial and Hispanic Intermarriages." Population Bulletin 60(2):1-36.

Lichter, Daniel, Julie Carmult and Zhenchao Qian .2011. "Immigration and Intermarriage among Hispanics: Crossing Racial and Generational Boundaries." Sociological Forum 26(2): 241-264.

Lieberson, Stanley, Mary C. Waters, and National Committee for Research on the 1980 Census. 1988. From Many Strands: Ethnic and Racial Groups in Contemporary America. New York: Russell Sage Foundation.

Long, J. Scott and Jeremy Freese, 2006. Regression Models for Categorical Dependent Variables Using Stata. $2^{\text {nd }}$ ed. Texas: Stata Press.

Massey, Douglas S. and Nancy A. Denton. 1993. American Apartheid: Segregation and the Making of the Underclass. Cambridge, MA: Harvard University Press.

Merton, Robert. 1941. "Intermarriage and the Social Structure: Fact and Theory." Psychiatry 4(1):361-374.

Monahan, Thomas P. 1970. “Are Interracial Marriages Really Less Stable?" Social Forces 48(4): 461-473.

. 1976. "An Overview of Statistics on Interracial Marriage in the United States, with Data on Its Extent from 1963-1970," Journal of Marriage and the Family 38(2): 223-231.

Osborne, Jason W. 2015. Best Practices in Logistic Regression. Thousand Oaks, CA: Sage Publications.

Qian, Zhenchao. 1997. "Breaking the Racial Barriers: Variations in Interracial Marriage Between 1980 and 1990." Demography 34(2):263-276. 
Qian, Zhenchao and Daniel T. Lichter. 2007. "Social Boundaries and Marital Assimilation: Interpreting Trends in Racial and Ethnic Intermarriage." American Sociological Review 72(1): 68-94.

Qian, Zhenchao and Daniel T. Lichter. 2011. Changing Patterns of Interracial Marriage in a Multiracial Society. Journal of Marriage and Family 73(5):1065-1084.

Raudenbush, Stephen W. and Anthony S. Bryk. 2002. Hierarchical Linear Models: Applications and Data Analysis Methods. Second Edition. Thousand Oaks, CA: Sage Publications.

Robinson, W.S. 1950. "Ecological Correlations and the Behavior of Individuals" American Sociological Review 15(1): 351-357.

Rosenfeld, Michael J. 2005. "A Critique of Exchange Theory in Mate Selection." American Journal of Sociology 110(5):1284-1325.

Rosenfeld, Michael J. 2007. The Age of Independence: Interracial Unions, Same-Sex Unions, and the Changing American Family. Cambridge, MA: Harvard University Press.

Rosenfeld, Michael J. 2010. "Still Weak Support for Status Exchange Theory." American Journal of Sociology 115(4):1264-1276.

Ruggles, Steven, Katie Genadek, Ronald Goeken, Josiah Grover, and Matthew Sobek. 2015. "Integrated Public Use Microdata Series: Version 6.0 [Machine-Readable Database]."

South, Scott J. and Steven F. Messner. 1986. "Structural Determinants of Intergroup Association: Interracial Marriage and Crime." American Journal of Sociology 91(6):1409.

Tucker, M. Belinda and Claudia Mitchell-Kernan. 1990. "New Trends in Black American Interracial Marriage: The Social Structural Context. Journal of Marriage and the Family 52(1):209-18.

U.S. Census Bureau. 2010. "2010 Census Shows Interracial and Interethnic Married Couples Grew by 28 Percent over Decade.” Washington D.C.

Van den Berghe, Pierre L. 1960. "Hypergamy, Hypergenation, and Miscegenation," Human Relations 13(1): 83-91.

Yancey, George A. 2002. "Who Interracially Dates: An Examination of the Characteristics of Those Who Have Interracially Dated," Journal of Comparative 
Family Studies 33(2): 178-190. 